\title{
La Universidad Laboral de Albacete (1974-75), un episodio olvidado en el legado arquitectónico de Julio Cano Lasso
}

\author{
María-Elia Gutiérrez-Mozo ${ }^{1}$ | José Parra-Martínez ${ }^{2}$ | Andrés Martínez-Medina ${ }^{3}$ \\ Recibido: 11-03-2019 | en su versión final: 02-11-2019
}

Resumen

\begin{abstract}
La Universidad Laboral de Albacete (1974-75), obra de Julio Cano Lasso, se implanta discretamente en un "no lugar" a las afueras de una "ciudad sin carácter". Alejada de cualquier foco mediático, apenas ha tenido difusión, por lo que el principal objetivo de este artículo es contribuir a su recuperación historiográfica y crítica. Para ello se aporta el primer estudio pormenorizado del edificio en relación tanto a su contexto inmediato como al conjunto de la producción y del pensamiento arquitectónico de su autor. El análisis del mismo ofrece algunas claves para reconocer y valorar su magisterio en la creación de un hábitat accesible e integrador, durable y mutable, que aún sirve y dignifica la vida de sus usuarios. Se distinguen cuatro ejes metodológicos: la investigación bibliográfica, fundamentalmente de las monografías y escritos del arquitecto; la investigación de fuentes históricas en los archivos de la Administración y profesional de Cano Lasso; el análisis comparativo de la obra con otras universidades laborales del autor, apuntando a una determinada genealogía moderna; $\mathrm{y}$, finalmente, el trabajo de campo, entrevistando al colaborador del arquitecto y a los responsables del centro pero, sobre todo, convirtiendo la experiencia de la arquitectura, en diferentes estaciones y momentos de la actividad del edificio, en un dato irremplazable. Esta obra, próxima en el espacio y en el tiempo, constituye un certero ejercicio de sobriedad y generosidad que pone en juego mínimos recursos con máximas aspiraciones, atendiendo, desde su compromiso con lo público, a lo necesario con lo estrictamente necesario.
\end{abstract}

Palabras clave: tradición y modernidad; microcosmos; historiografía y lugar

Citación

Gutiérrez, M. et al. (2020). La Universidad Laboral de Albacete (1974-75), un episodio olvidado en el legado arquitectónico de Julio Cano Lasso. ACE: Architecture, City and Environment, 15(43), 7316. DOI: http://dx.doi.org/10.5821/ace.15.43.7316

\footnotetext{
Profesora Titular de Universidad, Composición Arquitectónica, Departamento de Expresión Gráfica, Composición y Proyectos, Escuela Politécnica Superior, Universidad de Alicante (ORCID: 0000-0002-53687593, WOS Researcher ID: B-8589-2016, Scopus Author ID: 55842906600); ${ }^{2}$ Profesor Contratado Doctor, Composición Arquitectónica, Departamento de Expresión Gráfica, Composición y Proyectos, Escuela Politécnica Superior, Universidad de Alicante (ORCID: 0000-0003-0142-0608, wOS Researcher ID: 1-38282016, Scopus Author ID: 56022499000); ${ }^{3}$ Profesor Titular de Universidad, Composición Arquitectónica, Departamento de Expresión Gráfica, Composición y Proyectos, Escuela Politécnica Superior, Universidad de Alicante. (ORCID: 0000-0002-5309-9310, wOS Researcher ID: C-4296-2015, Scopus Author ID: 56024428600). Correo de contacto: eliagmozo@ua.es
}

ACE, 15 (4.3) CC BY-ND 3.0 ES | UPC Barcelona, España | La Universidad Laboral de Albacete (1974-75), un episodio olvidado en el legado arquitectónico de Julio Cano Lasso. DOI; http://dx.doi.org/10.5821/ace.15.43.7316 


\section{The Universidad Laboral of Albacete (1974-75), a long- forgotten part of Julio Cano Lasso's architectural legacy}

\section{Abstract}

Keywords: tradition and modernity; microcosm; historiography and place

\section{El contexto. Periferia geográfica y mediática: en un lugar de La Mancha}

En las monografías de Julio Cano Lasso (Madrid, 1920-1996), la Universidad Laboral de Albacete (197475), proyectada junto a Ramón Campomanes, aparece en las tres primeras (Cano, 1980, pág. 102; Cano, 1988, pág. 110 y CSCAE, 1992, pág. 89). Si bien deja de hacerlo ya en las dos de 1995 (primera edición de Munilla-Lería y catálogo de la exposición del Ministerio de Obras Públicas, Transportes y Medio Ambiente), así como en la italiana de 1996 (Electa), precisamente cuando la recopilación de sus obras más importantes ve la luz bajo el título de Estudio Cano Lasso, en lugar de Julio Cano Lasso, pues se pretende dejar constancia de los cambios introducidos, en los procesos y en los resultados, tras la incorporación al despacho de sus cuatro hijos arquitectos: Diego en 1981, Gonzalo y Alfonso en 1988 y Lucía en 1992 (Cano, 1995). Además, cuando esta obra había sido publicada, siempre había comparecido de forma modesta, no pasando nunca de una página. Es representativa al respecto su presencia en el libro de la Fundación Antonio Camuñas (1988, pág. 110), donde la referencia se limita a una fotografía y unas breves líneas que tratan dos de los temas claves en la arquitectura de su autor: la ciudad y la materialidad, determinantes también en esta obra.

Parece que cuando la producción del Estudio Cano Lasso alcanza dimensiones considerables y su comunicación requiere una muestra más sintética, la Universidad Laboral de Albacete desaparece del listado en el que, sin embargo y con cierto peso, permanecen las de Almería (1973-74) — para Centellas (1993, pág. 17) "el mejor edificio de la ciudad"- y Ourense (1974-75). Es significativo que la 
de Lardero, Logroño (1973-74), en la que Campomanes también es coautor, no entrase nunca a formar parte del reducido inventario de Julio Cano Lasso - las discrepancias con la contrata y la ejecución estarían en el origen de esta ausencia (Robles II, 2014) -, recogiéndose solo en el libro Arquitectura de Logroño (García-Pozuelo y Hernández, 1980) publicado por la Delegación en Logroño del entonces Colegio de Arquitectos de Aragón y La Rioja. En este panorama editorial se comprueba que la Universidad Laboral de Albacete, habiendo sido escogida por su autor para las primeras ediciones monográficas sobre su trabajo (la compilada por Xarait, en 1980, y las correspondientes al premio Antonio Camuñas de Arquitectura, en 1987, y a la Medalla de Oro de la Arquitectura, en 1991), se olvida en posteriores antologías, con lo que ello conlleva de pérdida de impacto. De este modo la obra de Albacete se mantiene al margen de cualquier interés mediático, pasando desapercibida a los ojos de los estudiosos -es llamativo, en este sentido, que, en su investigación, Pablo Basterra (2016) solo atribuya dos universidades laborales a Cano Lasso: Ourense y Almería-. Esta sería, pues, la primera razón por la que este artículo pretende recuperarla: tanto para reintroducirla en los circuitos de la información, como para insistir en su valoración como pieza del patrimonio arquitectónico español del siglo XX, a la que recientemente ha contribuido también su inclusión en el catálogo extendido del DOCOMOMO Ibérico (1965-75).

Pero hay más razones. Por un lado, supone la última de las universidades laborales desarrollada por el régimen de Franco, ofreciendo una estampa de la evolución del aparato estatal que, desde el Ministerio de Trabajo, promovió esta política docente durante más de tres décadas, entre la Universidad Laboral de Gijón y la de Albacete. A lo largo de ese tiempo, la apuesta por la formación universitaria en detrimento de la profesional, fue diluyendo el número de campus y su dimensión, desdibujándose paulatinamente el proyecto ideológico de las universidades laborales, especialmente cuando este fue asumido por el Ministerio de Educación y Ciencia, que definió la especificidad de su docencia a través de la Ley General de Educación de 1970. De esta norma son consecuencia los 'Centros de Universidades Laborales', nueva denominación para todos los que se fundan a partir de ese momento, entre los que Albacete se erige como el último baluarte de la enseñanza 'obrera' surgida del impulso falangista. Por otro lado, el propósito de este artículo es contribuir a recuperar la memoria, literal y metafóricamente perdida, de un edificio que, aún en mayor medida que otros de su mismo programa y ciclo histórico, ha sido desdeñado por la crítica y los medios profesionales, debido tanto a su situación como, probablemente también, a las connotaciones de una tipología demasiado representativa de una determinada etapa política (Basterra, 2012). Pero, además, frente a este olvido, conviene señalar que la obra de Albacete ha resistido encomiablemente el paso del tiempo, en parte, gracias a su abstracción, materialidad y excelente factura, lo que la distingue de otras universidades laborales de su autor -Almería, por ejemplo-, que no han envejecido tan dignamente, como el propio Cano (1993) lamentaría. Tres fundados motivos sustentan, pues, la reivindicación de este complejo educativo y su condición patrimonial: su interés histórico; su calidad arquitectónica e imagen de modernidad que, siendo expresiva del final del Desarrollismo y vinculada a la denominada Escuela de Madrid, pugna por superar el Movimiento Moderno sin renunciar a sus enseñanzas; y, por último, su buen estado de conservación y su uso a pleno rendimiento en la actualidad.

Asimismo, conviene recordar que, habitualmente, cuando se efectúa una selección de proyectos para presentar de forma panorámica la trayectoria de un arquitecto, se procura atender tanto a criterios de calidad (refrendados con premios o publicaciones), como a criterios de representatividad y singularidad en el conjunto de la producción del autor. En el caso de Julio Cano Lasso, la tipología de universidades laborales, de las que construyó cuatro, quedaba bien representada con las de Almería y Ourense y, además, la utilización del ladrillo como material protagonista de su obra podía ilustrarse con varios centros educativos coetáneos como los de Formación Profesional de Vitoria, Salamanca y Pamplona (1972-74) (Cano, 2001). Por ello, esta omisión quizá pueda deducirse también de las propias palabras de Cano Lasso respecto al lugar donde se ubica: "Albacete es una ciudad sin carácter" (Cano,

ACE, 15 (4.3) CC BY-ND 3.0 ES | UPC Barcelona, España | La Universidad Laboral de Albacete (1974-75), un episodio olvidado en el legado arquitectónico de Julio Cano Lasso. DOI: http://dx.doi.org/10.5821/ace.15.43.7316 
1988, pág. 110). Sin embargo, esta afirmación no es peyorativa, sino la expresión 'llana' de una realidad constatada por el autor, que amaba las ciudades históricas, esas que, a diferencia de Albacete, dibujó con esmero (Cano, 1985) para explicar cómo geografía e historia se funden en un patrimonio urbano y arquitectónico capaz de suscitar emoción (Gutiérrez-Mozo y Arnau, 2019). (Figura 1)

Figura 1. Dibujo de Salamanca en un sobre franqueado en Cuenca el 15 de octubre de 1984

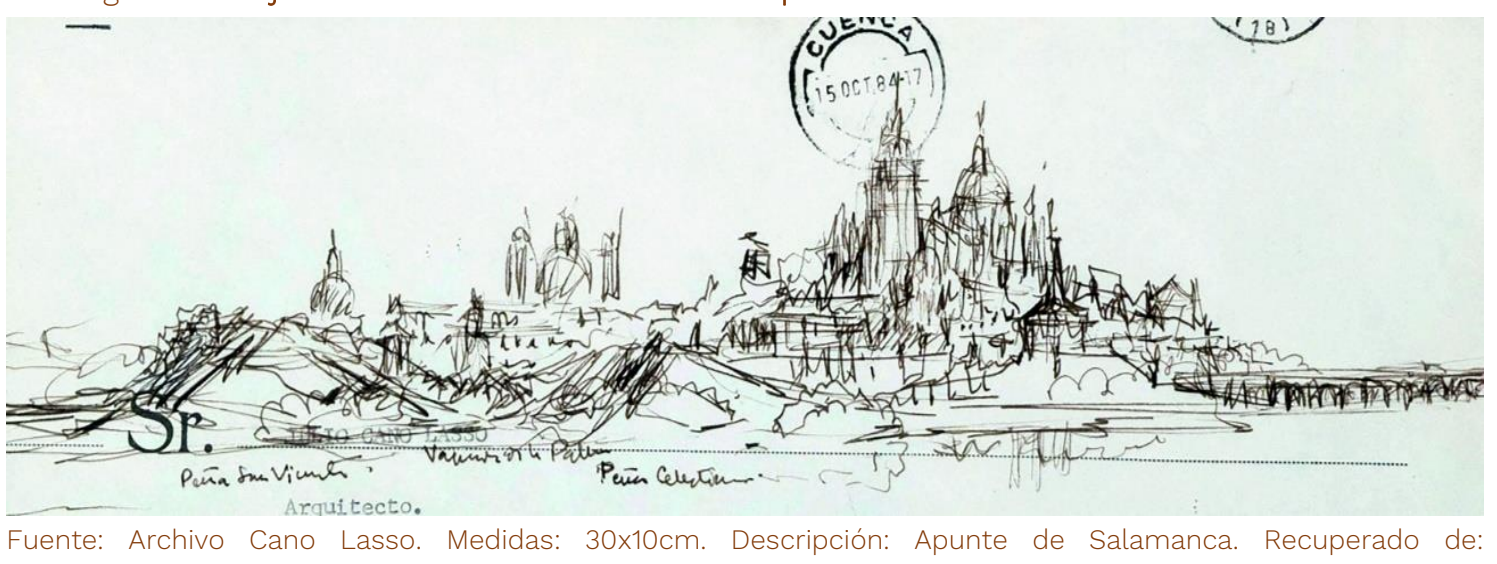

http://lasso.archivosarquitectos.com/es/original/project/62.

No obstante, con la misma naturalidad con que Cano Lasso dice que "Albacete es una ciudad sin carácter", afirma que en el entorno próximo a su solar existen "arquitecturas modernas en ladrillo de calidad" (Cano, 1988, pág. 110). Conviene, por tanto, preguntarse cuáles eran estas obras para entender su propia propuesta. En 1968, Antonio Escario, José Antonio Vidal, José Vives y Arturo Mongrell habían levantado el Centro de Recuperación de Inválidos (Arnau, 2010) (actualmente, Oficinas de la Consejería de Bienestar Social) en la esquina de la carretera de Madrid con la calle de Jesús del Gran Poder, un edificio racionalista de ladrillo compuesto por franjas horizontales que se alternan con el hueco corrido, ligeramente rehundido y trabado por paños de enfoscado. Alejado de este enclave, en la circunvalación, y próximo al entronque de la carretera de Valencia y Alicante, pero con similares lenguaje y acabados, el mismo equipo había proyectado y construido el Hospital Universitario (197074) (Arnau, 2010). La otra preexistencia relevante en la que, con seguridad, Julio Cano Lasso reparó se hallaba en la misma avenida de su solar, volcada a la carretera de Madrid: se trataba de la maltería El Águila, de Carlos Belmonte, de 1959. Las fotografías que se conservan (Valero, 2015) muestran una disposición de los bloques paralela a la carretera con el silo en primera línea y, tras él, los edificios de oficinas, quedando en último plano el resto de instalaciones industriales de la fábrica. La composición alternaba en todo el conjunto el hormigón visto, marcando el ritmo estructural en el arranque de los edificios, y los grandes paños de ladrillo caravista rojo. Estas son las obras "modernas en ladrillo de calidad" que Julio Cano Lasso pudo encontrar en Albacete hacia 1974. A ellas cabría añadir una discreta promoción de viviendas sociales publicada en las páginas de la revista Arquitectura (De la Joya y Barbero, 1959), también ejecutada en ladrillo visto. Y todo ello en una ciudad voraz como pocas con su patrimonio arquitectónico (Chueca, 1977). Por su parte, la calle Ancha, a modo de pequeña Gran Vía local (Gutiérrez-Mozo, 2004), mostraba piezas notables del primer tercio del siglo XX, más o menos aisladas entre los vacíos y los excesos de las primeras edificaciones en altura.

Posiblemente sea este el panorama al que el profesional se refiere con la expresión "falta de carácter", que bien puede traducirse por falta de referencias - más allá de los citados edificios modernos-, por carencia de un tipo de arquitectura popular reconocido, un material predominante o un relieve natural condicionante. Estos temas - lo popular, lo material y lo topográfico- nutren los proyectos de la Universidad Laboral de Ourense (Cano, 2003; Río, 2011) y la de Almería (Valero, 2008).

ACE, 15 (43) CC BY-ND 3.0 ES | UPC Barcelona, España | La Universidad Laboral de Albacete (1974-75), un episodio olvidado en el legado arquitectónico de Julio Cano Lasso. DOI: http://dx.doi.org/10.5821/ace.15.43.7316 
Esta última presenta un esquema organizativo precursor del de Albacete y ambas obras entroncan, respectivamente, con la arquitectura gallega en piedra y la arquitectura andaluza encalada, es decir, con materiales tradicionales de construcción. Sobre estas dos universidades Cano Lasso escribe: "Aparecen reflejadas en la arquitectura, casos de Almería y Ourense, las condiciones del clima y del lugar, que fueron tenidos muy en cuenta, aquí se reproduce un encuentro con lo popular” (Cano, 1995, pág. 13).

Ante la ausencia de estímulos que susciten el proyecto, Cano Lasso responde desde lo que él mismo llama la "abstracción", que alcanza tanto a la disposición de la planta (ejes y patios) como al material básico, el ladrillo, de vocación universal y al que el autor se refiere, en diversas ocasiones, como "material intemporal" (Cano, 1991a, pág. 42) o "materiale senza tempo" (Cano et al., 1997), ya que se encuentra en las arquitecturas de todas las épocas y culturas. Esa condición del ladrillo es la que lo hace acertado para Albacete, un "no lugar", o un lugar de paso. Es más, entre las referencias cultas del arquitecto, algunos maestros, como Alvar Aalto, habían hecho un uso ejemplar del ladrillo en equipamientos universitarios (Baker House, 1948), devolviéndolo a un primer plano como material óptimo (tanto exterior como interior), convirtiéndolo en protagonista por sus múltiples posibilidades constructivas y expresivas; hecho repetido en las facultades de Ingeniería de Leicester y de Historia de Cambridge, ambas de James Stirling y James Gowan, reproducidas en 1964 en las páginas de Arquitectura. El ladrillo estaba aceptado como moderno: la modernidad no radicaba en el material, sino en la arquitectura a la que daba vida. Cano Lasso también había reconocido su admiración por las obras de la Escuela de Ámsterdam (Vreeze y Ouwehand, 2007), por su sincera utilización de los lenguajes asociados a las tradiciones locales como puente entre el pasado y el futuro y, particularmente, por los edificios de Dudok en Hilversum, con sus "acusados ritmos horizontales y contrapuntos verticales, y en general, con el empleo austero y masivo de ladrillo" como un eco que resonaba en su obra (Nueva Forma, 1972, pág. 22). Y, probablemente, en su subconsciente estuviese también Berlage, figura tutelar de las escuelas holandesas del primer tercio del siglo XX y ejemplo de ética manifestada a través de la construcción y su identificación con el progreso social. Embebido del espíritu de esa modernidad, no entregada todavía a las obsesiones de la pura forma ni a la fabricación de imágenes, incluso el propio Mies elaboraría un radiante ejercicio de composición con el ladrillo y su simbología proletaria en su expresionista Monumento a Rosa Luxemburgo (1926).

Quizás, precisamente por la destrucción del patrimonio que ha afectado indiscriminadamente a arquitecturas de todo tiempo y tipo y por su propia condición de ciudad de tránsito, siempre provisional y esperando un destino claro, en Albacete, la Universidad Laboral es una pieza de primera magnitud: lo es en sí misma, por su proyecto racional y culto, y lo es en relación a su contexto, donde el panorama de la periferia, salvando algunas obras como las citadas de Escario, adolece del valor de conjunto urbano. Es significativo cómo la ciudad se ha ido dotando de nuevas arquitecturas pretendidamente estelares (como el Palacio de Congresos de Frechilla y López-Peláez) (Arnau, 2010) y, a la vez, se ha olvidado de obras anteriores, como esta de Cano Lasso. Probablemente se cumple la máxima de que la arquitectura moderna es aquella que se relaciona activamente con los medios de comunicación y, en este sentido, la fortuna de la Universidad Laboral de Albacete ha sido muy escasa. Cabe añadir que, hasta que Diego Cano Pintos no ha puesto a disposición de esta investigación la documentación original que su estudio conserva del proyecto, el expediente de 1974 no se había hallado (ni planos ni memoria) en los archivos consultados, que incluyen el Archivo Municipal y el Archivo Provincial de Albacete, el Archivo General de la Administración y el del Ministerio de Educación, ambos en Alcalá de Henares, así como el Archivo Central del Ministerio de Trabajo, Migraciones y Seguridad Social, en Madrid, lo cual, además de haber dificultado la tarea de conocer y dar a conocer la obra, evidencia una falta de interés generalizado hacia la misma.

Y, si en la ciudad de Albacete su Universidad Laboral es una pieza de incuestionable importancia, en la producción de su autor ocupa una posición central, como de hito en mitad del camino o de punto

ACE, 15 (4.3) CC BY-ND 3.0 ES | UPC Barcelona, España | La Universidad Laboral de Albacete (1974-75), un episodio 5 olvidado en el legado arquitectónico de Julio Cano Lasso. DOI: http://dx.doi.org/10.5821/ace.15.43.7316 
de inflexión en su madurez. Julio Cano Lasso se había titulado en 1949, a los 29 años, y este proyecto lo redacta y construye un cuarto de siglo después, cuando tiene 55 años. Dado que el arquitecto continuaría trabajando hasta su muerte, en 1996, existen aún más de dos décadas de arquitectura después de este edificio. Otra circunstancia que caracteriza la concepción del proyecto y la construcción de la obra es la gran cantidad de trabajo a la que, en ese momento, hace frente Julio Cano Lasso. Este hecho le lleva a colaborar con colegas jóvenes, algunos antiguos alumnos. Así, en las obras apuntadas hasta ahora (todas de los años 70), Ramón Campomanes participa en las Universidades Laborales de Albacete y Logroño. En la de Almería colaboran Campo Baeza, Más Guindal y Martín Escanciano. En la de Ourense, Sanz y Ortiz Carbajal. Los Centros de Formación Profesional de Salamanca, Vitoria y Pamplona los realiza con Alberto Campo Baeza y la Caja Provincial de Ahorros de Cuenca, con Alejandro Blond (Cano, 2001).

\section{El texto: proyecto y obra. Centro de Universidades Laborales de Albacete}

\subsection{Los programas docente y residencial}

El programa funcional y el proyecto educativo de las universidades laborales son indudablemente complejos (Zafrilla, 1998). A esta complejidad, derivada de la variada formación impartida y de la necesidad de espacios específicos, se suman otras dos cuestiones. Primera: su implantación periférica respecto de las ciudades, en solares capaces de albergarlas. Segunda: su alumnado, mayoritariamente interno, de manera que los centros debían atender tanto los requerimientos docentes como dar respuesta a las necesidades de la vida cotidiana de sus habitantes. Esta condición de autosuficiencia de las universidades laborales - Robles (2014 I, pág. 65) las llama "conjuntos autónomos de la ciudad" - explica que su organigrama contemplara, pormenorizadamente, la atención a las actividades de socialización, ocio y esparcimiento, entre las que destacan las deportivas y las culturales, apoyadas tanto por dotaciones propias como por espacios de relación. (Figura 2)

Figura 2. Emplazamiento de la Universidad Laboral de Albacete

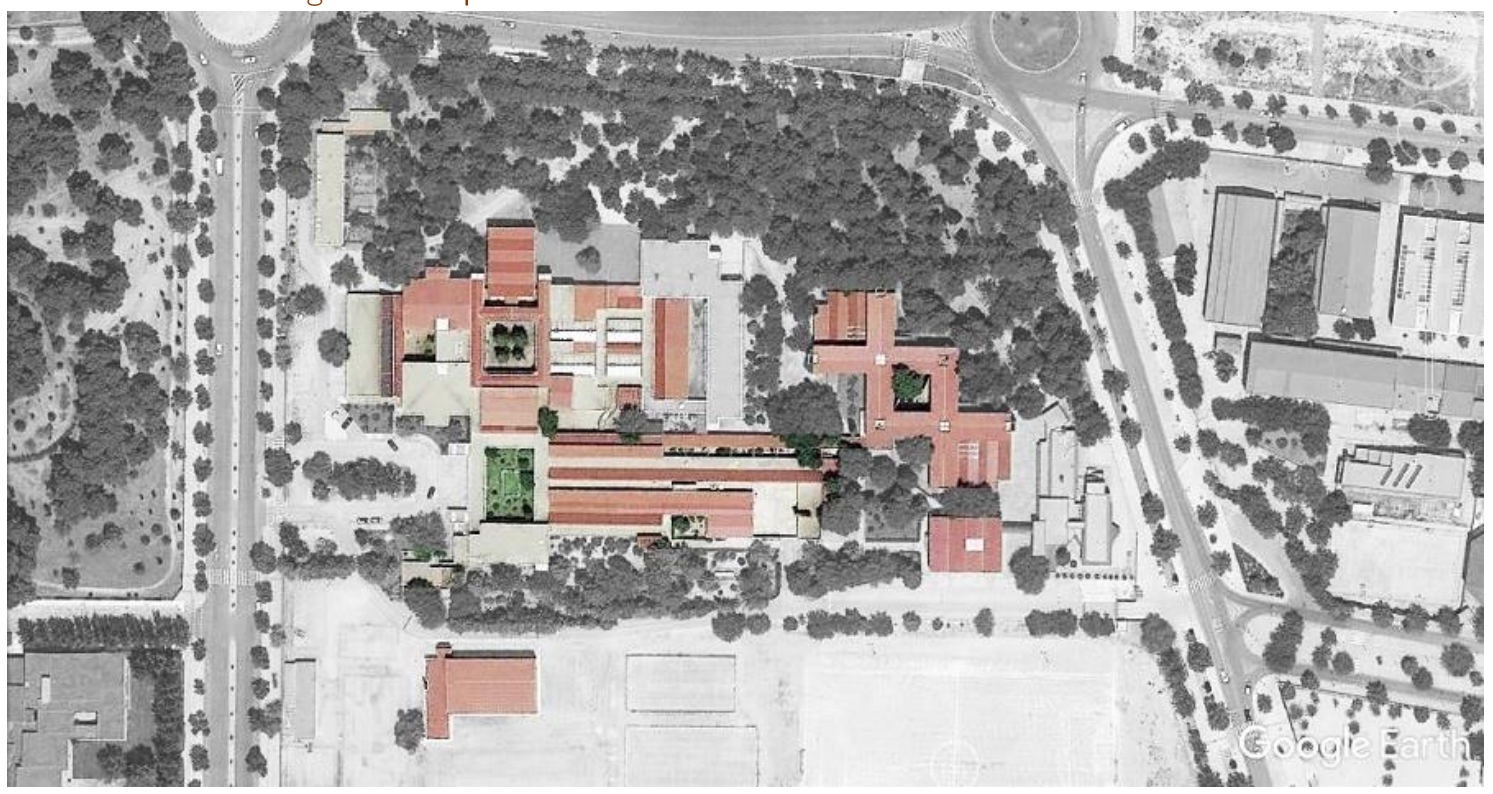

Fuente: Elaboración propia a partir de vista del satélite de Google Maps.

ACE, 15 (43) CC BY-ND 3.0 ES | UPC Barcelona, España | La Universidad Laboral de Albacete (1974-75), un episodio

olvidado en el legado arquitectónico de Julio Cano Lasso. DOI: http://dx.doi.org/10.5821/ace.15.43.7316 
El 'Centro de Universidades Laborales de Albacete' se ubica en una parcela de 8 hectáreas alejada 1,5 kilómetros del centro urbano. Dicho solar hoy está delimitado por las actuales Avenida de la Mancha, Paseo de la Cuba y calle de Casas Ibáñez que, por entonces, definían un sector de la periferia norte, urbanizada en sus vías principales, sito entre el Canal de María Cristina y el polígono industrial Campollano -toponimia que remite a la condición horizontal de este territorio-, con vocación de colmatarse por su vecindad a la trama consolidada de la ciudad. El acceso principal se dispone por la Avenida de la Mancha y el conjunto discurre, básicamente, a lo largo de un eje perpendicular a ella hasta salir al encuentro de la calle de Casas Ibáñez, donde se ubica la entrada de servicio. La obra actúa de charnela entre una, hoy, frondosa zona verde - entonces recién plantada - recayente al Paseo de la Cuba y las pistas deportivas del complejo definidas a la vez que el centro universitario.

Se proyectó para 680 estudiantes: 400 internos y 280 externos y/o mediopensionistas. Su superficie construida es de $20.300 \mathrm{~m}^{2}$. El proyecto fue redactado a principios de 1974. Las obras, ejecutadas por la empresa Entrecanales y Távora con un presupuesto de 190 millones de pesetas, comenzaron ese mismo mes de junio y terminaron en otoño del siguiente año, inaugurándolas el Ministro de Trabajo, con la apertura del curso escolar 1975-76, el 11 de octubre de 1975 (ABC, 1975). Las enseñanzas impartidas eran Formación Profesional de Primero y Segundo (FPI y FPII) en las ramas de Confección Industrial, Electrónica e Idiomas; Bachillerato Unificado y Polivalente (BUP); Curso de Orientación Universitaria (COU); y Formación Profesional para adultos, en cursos intensivos y nocturnos. Dado que Cano Lasso recibió casi a la vez los encargos de las Universidades Laborales de Almería (197374), Lardero (1973-74) y Albacete (1974-75), se estudia la solución de la última en relación a sus inmediatas predecesoras, pues en los tres casos trabaja con la idea de edificio tapiz (Robles II, 2014) que se extiende sobre el terreno llano, al que se impone un orden racional para organizar jerárquicamente las funciones en planta y los volúmenes en sección. Se excluye del análisis comparativo Ourense (1974-76), cuya composición obedece tanto a la orografía como a la vinculación directa con su arquitectura vernácula (Río, 2011).

En el caso de la Universidad Laboral de Almería, la trama de la planta se genera por la intersección de dos pares de ejes perpendiculares cuyo cruce delimita un gran vacío o 'plaza central'. En la secuencia del acceso se concatenan, por este orden: vestíbulo (flanqueado a la derecha por la sala de conferencias y a la izquierda por la dirección), biblioteca, patio principal, cafetería, comedores, cocina y, al final, los servicios. Por su parte, la dirección ortogonal ordena, a la derecha del patio, las residencias masculina y femenina y, a la izquierda, las aulas, los talleres y los laboratorios. Una profusión de patios medianos y pequeños perfora la compacidad de los bloques e introduce luz y aire en los espacios interiores e intermedios. En la memoria del proyecto - parcialmente reproducida en la revista Arquitectura (Cano, 1976, pág. 80) - se afirma que estos patios, fácilmente transformables en "pequeños oasis, con microclima propio", pueden tener muy diversas funciones: "Unas veces sólo recreo de la vista y los sentidos; otros espacios de trabajo al aire libre, entoldados por las parras; otros, zonas de encuentro y relación".

En Almería, el número de puestos escolares es igual al de Albacete (680) y el de los internos casi también (402 frente a 400). En Lardero, los puestos son 600, de los que 320 son para internos (Robles I, 2014). En este caso, los pares de ejes principales se disponen paralelos, en lugar de perpendiculares, y desplazados: el de acceso replica, comprimiéndola, la secuencia descrita para Almería y, así, se prescinde del vestíbulo y de la biblioteca. A su derecha discurre el cuerpo docente, cuyo patio se conforma en la intersección de su propio eje con el que se crea perpendicular para engarzarlo con el eje de acceso: el aula magna - espacio académico y de representación- es el vínculo entre los dos patios replicados: el de la entrada y el docente. La peculiaridad de la Universidad Laboral de Lardero es que la residencia, con planta en forma de doble $X$, es exenta y se alinea con el cuerpo docente, así como también queda exento el pequeño bloque de servicios. Frente a la gran cantidad y variedad de medidas de patios de Almería, en Lardero se reducen a tres: el del acceso, el del cuerpo docente y el de la residencia. (Figura 3)

ACE, 15 (4.3) CC BY-ND 3.0 ES | UPC Barcelona, España | La Universidad Laboral de Albacete (1974-75), un episodio 7 olvidado en el legado arquitectónico de Julio Cano Lasso. DOI: http://dx.doi.org/10.5821/ace.15.43.7316 
Figura 3. Esquemas de las Universidades Laborales de Almería (arriba), Lardero

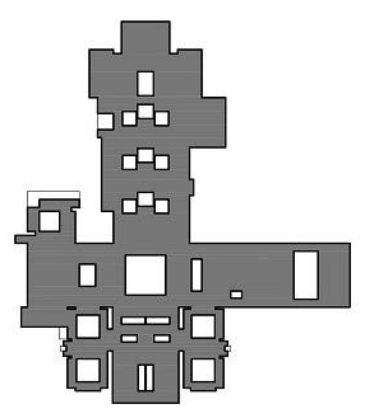

(centro) y Albacete (abajo)
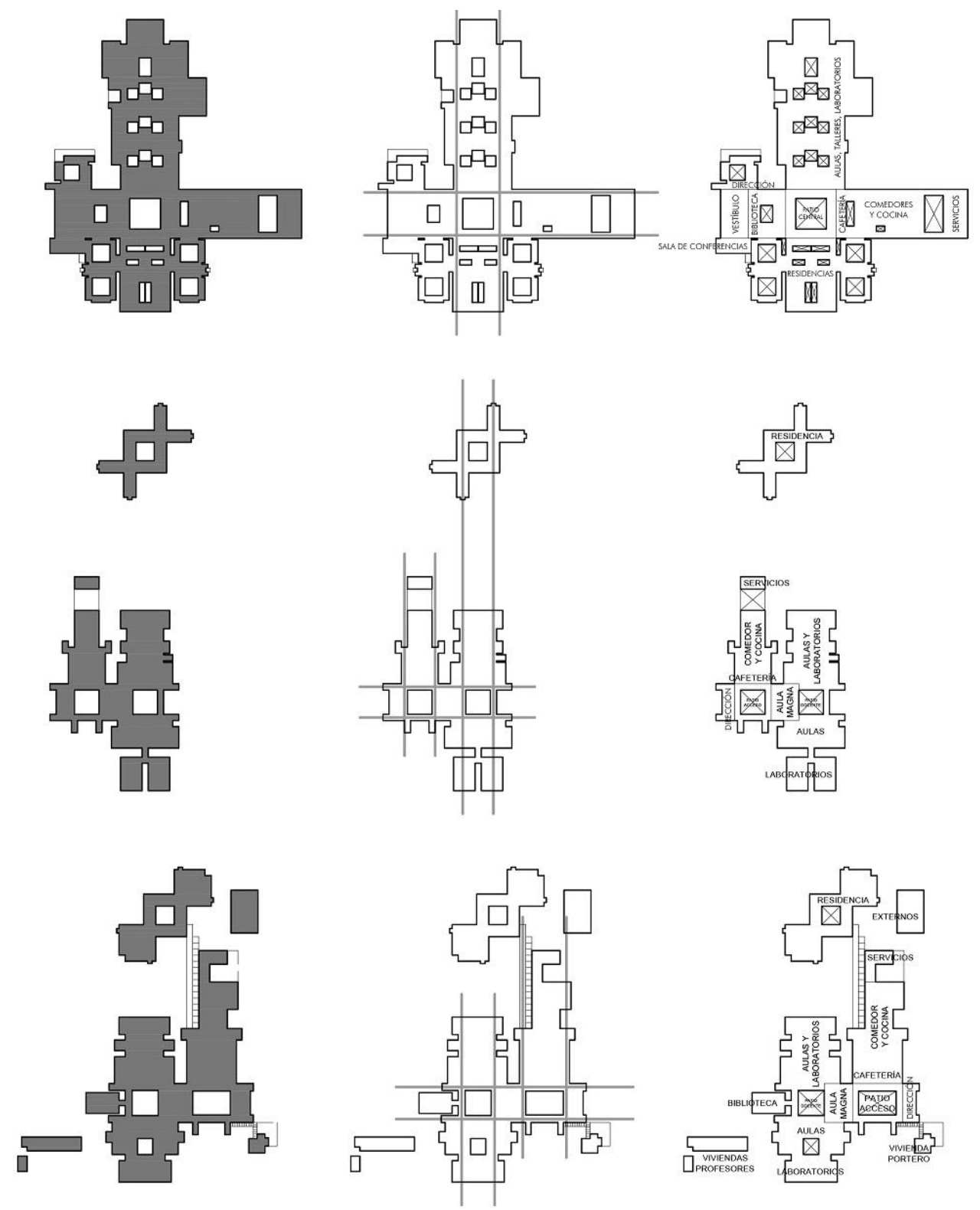

Fuente: Robles, La arquitectura de las Universidades Laborales españolas (1946-1978) I, 2014, pág. 119.

La Universidad Laboral de Albacete parte del esquema compositivo en planta de Lardero, surgido tras el de Almería, complejizándolo por su mayor número de estudiantes. El eje de acceso ordena la secuencia de patio, cafetería, comedor, cocina y pequeño bloque de servicios en $L$ girado 90․ A su izquierda, discurre paralelo el eje docente que se traba al anterior con la misma estrategia descrita para Lardero, es decir, generando un eje perpendicular a ambos mediante la secuencia de patios, la cual se remata, en el extremo al acceso, con la dirección y, en el otro, con la biblioteca recuperada en una ampliación posterior. Entre ambos patios, docente y de acceso, se inserta también el aula magna. La residencia, en forma de doble X cuyos brazos libres dan lugar a espacios comunitarios en planta baja, se vincula con el cuerpo de acceso y lo hace mediante un paso al aire libre, pero cubierto (Pié y Rubiralta, 2019). En la trama de la planta hay un total de cuatro patios, todos ellos diferentes

ACE, 15 (43) CC BY-ND 3.0 ES | UPC Barcelona, España | La Universidad Laboral de Albacete (1974-75), un episodio 8 olvidado en el legado arquitectónico de Julio Cano Lasso. DOI: http://dx.doi.org/10.5821/ace.15.43.7316 
en dimensiones y tratamiento: el de acceso es el mayor $(24 \times 16 \mathrm{~m})$, rectangular y con un estanque en medio de un manto de hierba que recuerda el del Ayuntamiento de Säynätsalo; el docente es cuadrado (16 × 16 m), pavimentado y arbolado; el patio de la residencia, también cuadrado $(12 \times 12 \mathrm{~m})$, arbolado y con jardín interior; y, finalmente, el patio entre aulas y laboratorios (10,5 x 10,5 m), con escasa vegetación. Las mallas reticulares de las plantas en los tres centros están emparentadas a través del empleo del mismo módulo base de $4 \times 4 \mathrm{~m}$ compartido con Almería y Lardero, lo cual permite reutilizar soluciones de diseño de las diferentes agrupaciones, optimizadas, de piezas docentes o residenciales. (Figura 4)

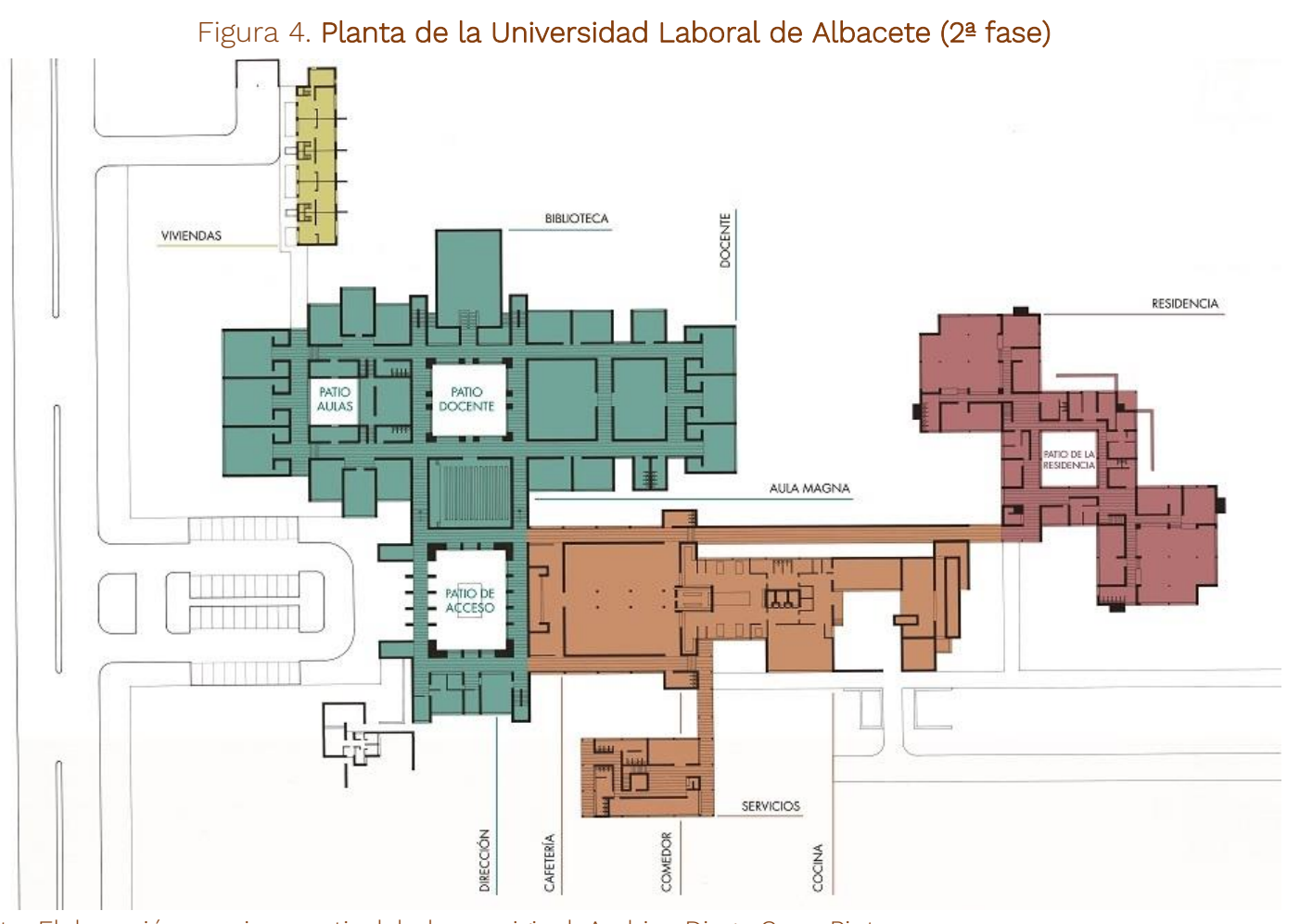

Fuente: Elaboración propia a partir del plano original. Archivo Diego Cano Pintos

\subsection{Planos de proyecto: la relevancia de las secciones}

La documentación de proyecto facilitada por Diego Cano Pintos consiste en 10 planos que se corresponden con 6 plantas y 4 secciones. Solo en cinco de estos documentos consta la fecha, los correspondientes a las secciones longitudinales de las áreas docentes y de formación profesional (n.․․ 2.A9, abril 1974); las secciones transversales de dichas áreas (n.․ 2.A10, abril 1974); las secciones transversales del área de dirección, comedores y servicios (n. 3.A10, abril 1974); una primera propuesta de ampliación que contempla el pabellón de externos, la biblioteca y las viviendas de directivos y profesores, sobre el plano de situación y emplazamiento (n.․ 01, 1975); y la propuesta definitiva en relación a cinco viviendas de directivos y a la biblioteca, estudiando otra posible solución para el pabellón de externos (n.ㅇ 01, octubre 1976). Los otros cinco planos, sin fecha, son: una expresiva planta de cubiertas, con sombras arrojadas a 45으, de la primera fase, en la que aparece, al fondo y replicando el esquema de la residencia, una edificación cuyo uso se desconoce y que nunca se construyó (¿viviendas para profesores?); una planta a lápiz en la que se plantea dos posibles ubicaciones de la hilera de viviendas; unas secciones, longitudinal y transversales, iguales a las de los planos de 1974; una planta de llenos y vacíos correspondiente al estado anterior a la construcción del pabellón de externos; y un plano de distribución de todo el conjunto a nivel de planta baja, del mismo momento que la anterior.

ACE, 15 (4.3) CC BY-ND 3.0 ES | UPC Barcelona, España | La Universidad Laboral de Albacete (1974-75), un episodio 9 olvidado en el legado arquitectónico de Julio Cano Lasso. DOI: http://dx.doi.org/10.5821/ace.15.43.7316 
La documentación gráfica no aporta, pues, alzados ni plantas de distribución de otros niveles, ni croquis con tanteos previos. Es muy significativo, en contrapartida, el número de secciones dibujadas (hasta un total de 15), que exhibe la complejidad espacial de un conjunto que, partiendo de una modulación cuadrada (en la cual se apoya la organización del vasto programa), articula una enorme variedad de soluciones confiada, en gran parte, a las cubiertas y, con ellas, a la luz. (Figuras 5, 6 y 7)

Figura 5. Secciones longitudinales de las áreas docentes y de formación profesional

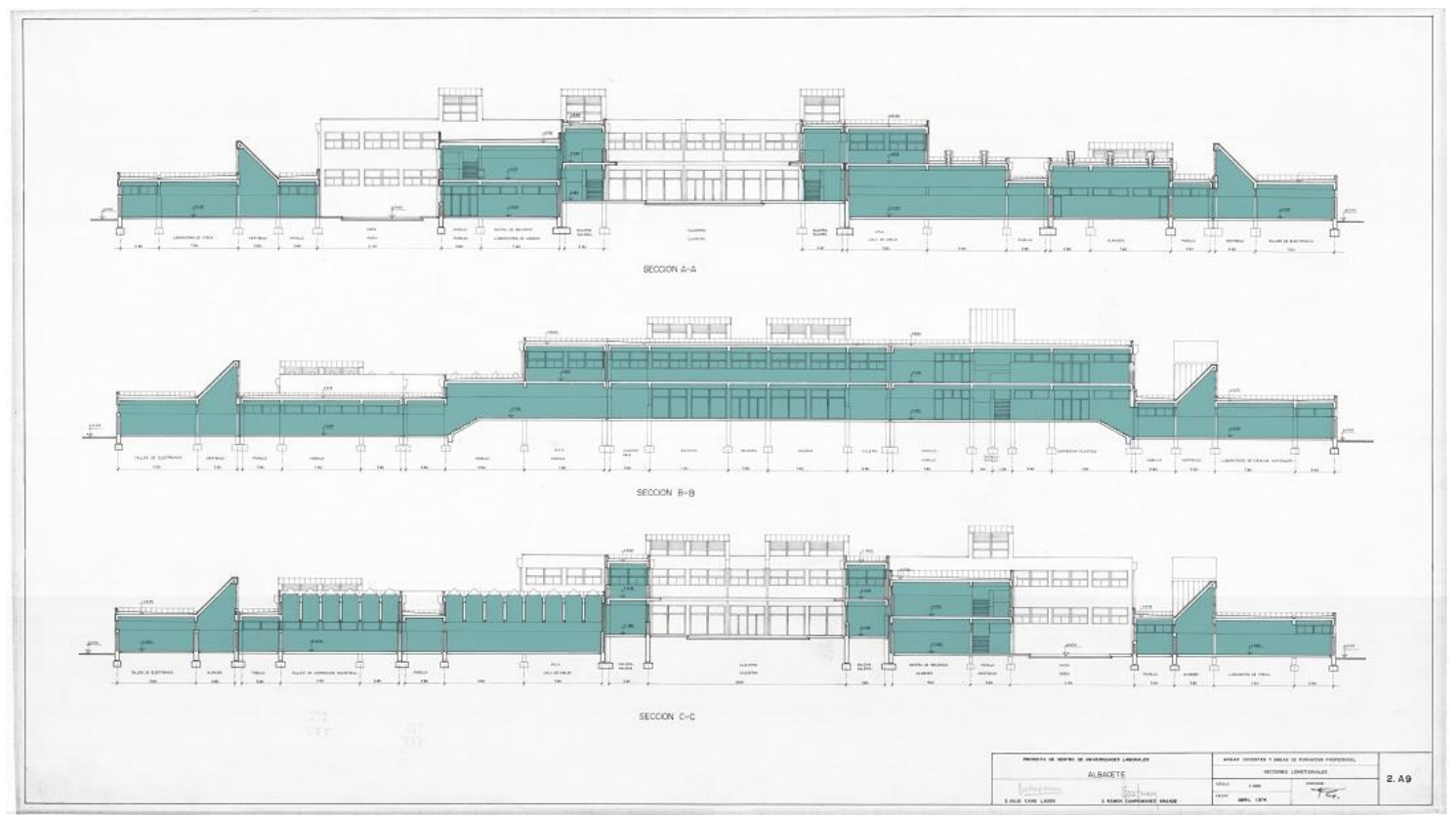

Fuente: Elaboración propia a partir del plano original. En azul, las áreas docentes. Archivo Diego Cano Pintos.

Figura 6. Secciones longitudinales de las áreas docentes y de formación profesional

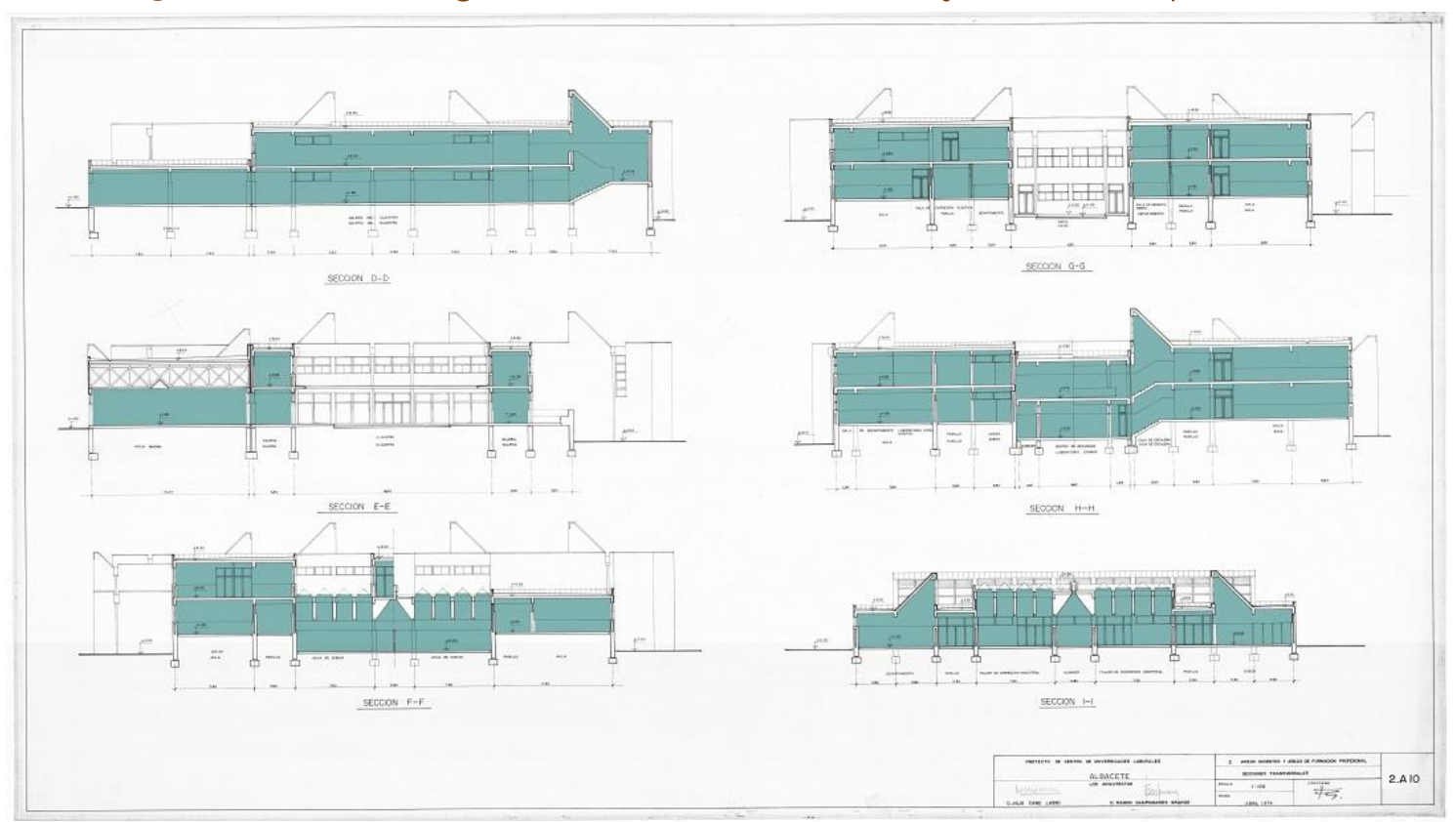

Fuente: Elaboración propia a partir del plano original. En azul, las áreas docentes. Archivo Diego Cano Pintos.

ACE, 15 (4.3) CC BY-ND 3.0 ES | UPC Barcelona, España | La Universidad Laboral de Albacete (1974-75), un episodio 
Figura 7. Secciones transversales del área de dirección, comedores y servicios

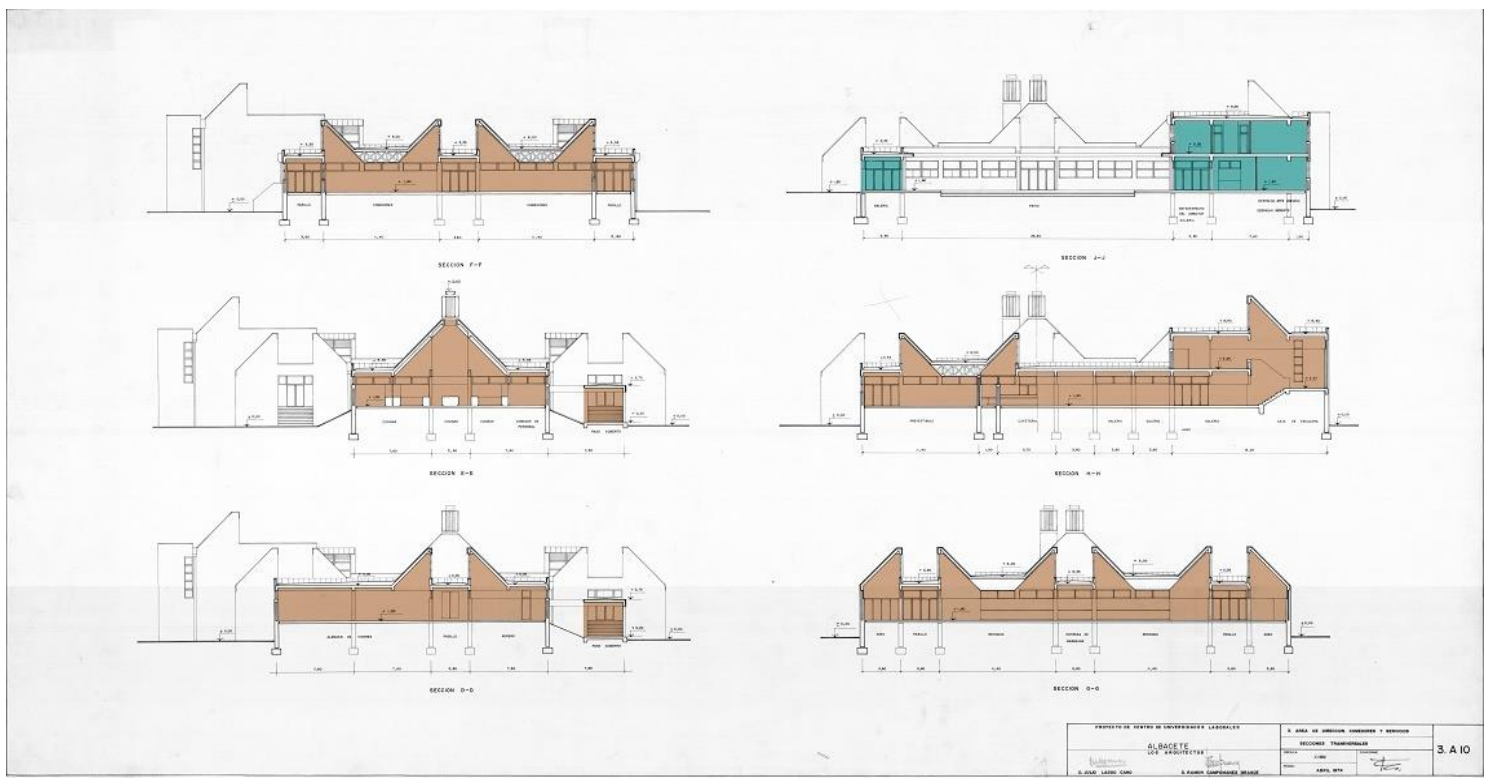

Fuente: Elaboración propia a partir del plano original. En marrón, las áreas de comedores y servicios. En azul, las áreas docentes y de dirección. Archivo Diego Cano Pintos.

Así, sobre el esquema de planta descrito, las diferentes cotas de suelo y de alturas de techo lo dotan de una gran variedad de soluciones espaciales que responden a las necesidades de cada una de las salas, generando una topografía en planta baja con diversas mesetas. La doble $X$ de la residencia presenta tres plantas, constituyendo de este modo la edificación más alta del conjunto; tienen dos plantas el pabellón de externos, la biblioteca, el patio docente, el aula magna, la zona de dirección y las aulas de transición entre el claustro y los laboratorios. Presenta una única planta el espacio que abrazan los lados no tangentes de la residencia, los laboratorios con los que se remata el principio y el final del eje docente y el deambulatorio alrededor del patio de acceso. También, toda el área de cafetería, comedor, cocina y servicios, así como los talleres, aunque en estos espacios lo llamativo de la solución diseñada para su iluminación merece mención aparte.

De hecho, el detalle constructivo previsto para la iluminación con luz natural llevaría al otro asunto apuntado: el de las cubiertas, cuya complejidad se plasma en el delicado plano con las sombras arrojadas. El proyecto original plantea para la mayoría del conjunto una serie de cubiertas planas salpicadas de lucernarios en aquellos espacios alejados del perímetro construido, entre ellos, los talleres alojados entre el patio docente y los laboratorios de remate, abrazados por aulas laterales. Además, en puntos clave, se propone unas singulares linternas que reelaboran formas anteriores similares a las empleadas en la Central de Comunicaciones por Satélite en Buitrago (1967) - pero que finalmente no se construyeron. (Figura 8)

No obstante, la solución constructiva más singular, y que genera una mayor riqueza espacial, es el recurso a los lucernarios resueltos levantando el forjado en una sección triangular pensada para captar la luz a través de un plano vertical de vidrio y hacerla resbalar al interior a través de su reflejo en el plano inclinado opuesto de la cubierta. Esta es la decisión de proyecto adoptada en todo el cuerpo de cafetería, comedor, cocina y servicios hasta acometer el deambulatorio del patio de acceso. Un paisaje quebrado cuyos accidentes 'montañosos' se van extendiendo a lo largo de diferentes longitudes, la mayor de las cuales se produce en el centro mismo del sistema y se abrevian en sus costados. Estas grandes líneas vertebradoras son paralelas a los ejes docente y de acceso y

ACE, 15 (43) CC BY-ND 3.0 ES | UPC Barcelona, España | La Universidad Laboral de Albacete (1974-75), un episodio 11 olvidado en el legado arquitectónico de Julio Cano Lasso. DOI: $\underline{\text { http://dx.doi.org/10.5821/ace.15.43.7316 }}$ 


\section{ACE Architecture, City and Environment}

e-ISSN 1886-4805

se orientan en la dirección noroeste-sureste. Reverberaciones de ellas se encuentran en el aula magna y, giradas 90, en los laboratorios de remate del eje docente. Resulta interesante la relación que los autores establecen entre la posición de este tipo de gran lucernario y los espacios a los que sirve, siempre comunes y compartidos: escaleras, cafetería, comedor y servicios, o bien necesitados de una iluminación suplementaria y doble desde planos opuestos, como en el caso de los bloques de laboratorios. La orientación de estos grandes paños de vidrio es siempre a noreste o noroeste, para que la luz entrante no genere deslumbramientos y sea lo más uniforme posible. (Figura 9)

Figura 8. Planta de cubiertas con sombras arrojadas (1a fase)

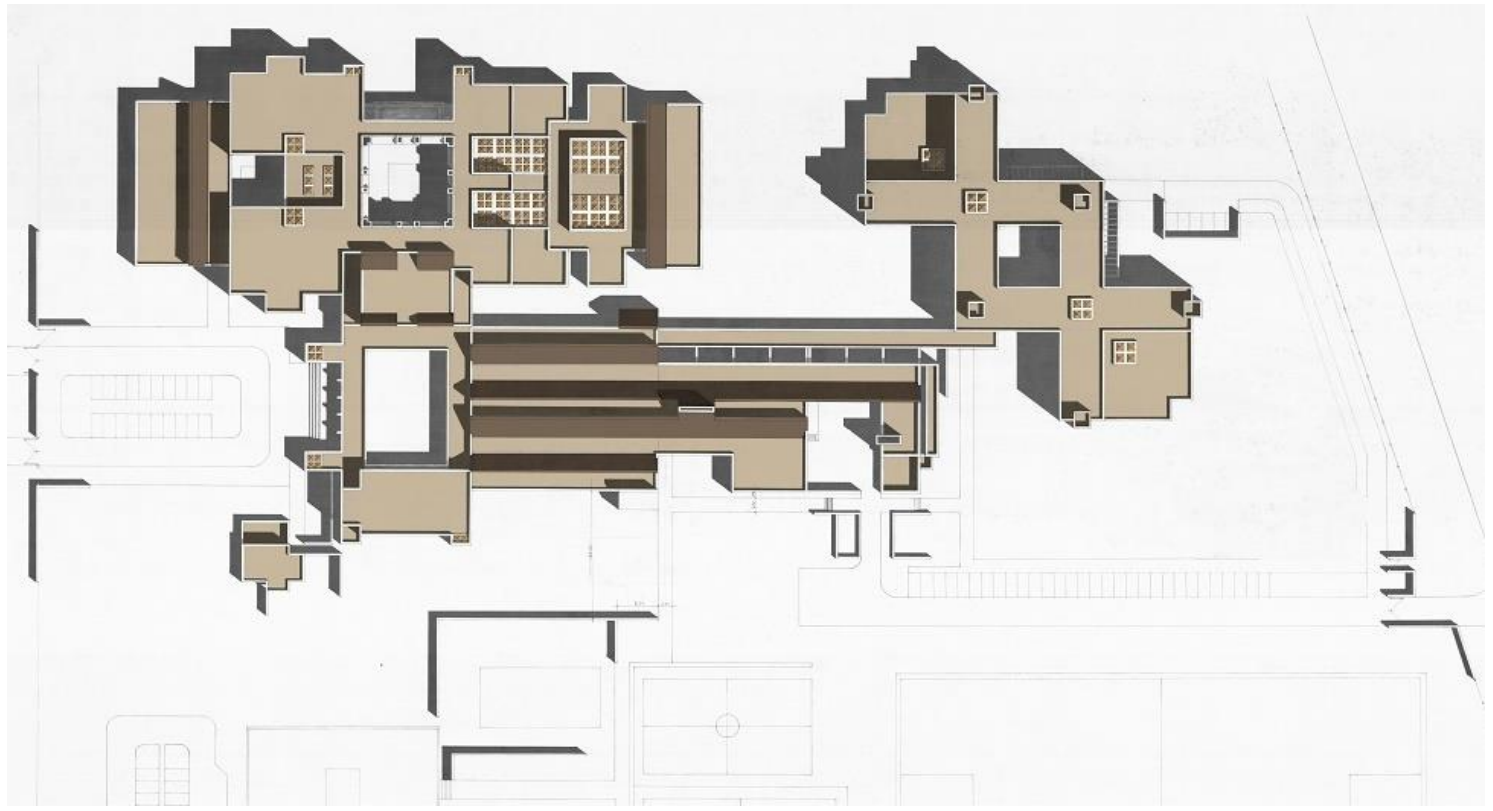

Fuente: Elaboración propia a partir del plano original. Archivo Diego Cano Pintos.

Figura 9. Universidad Laboral de Albacete. Imagen actual del comedor
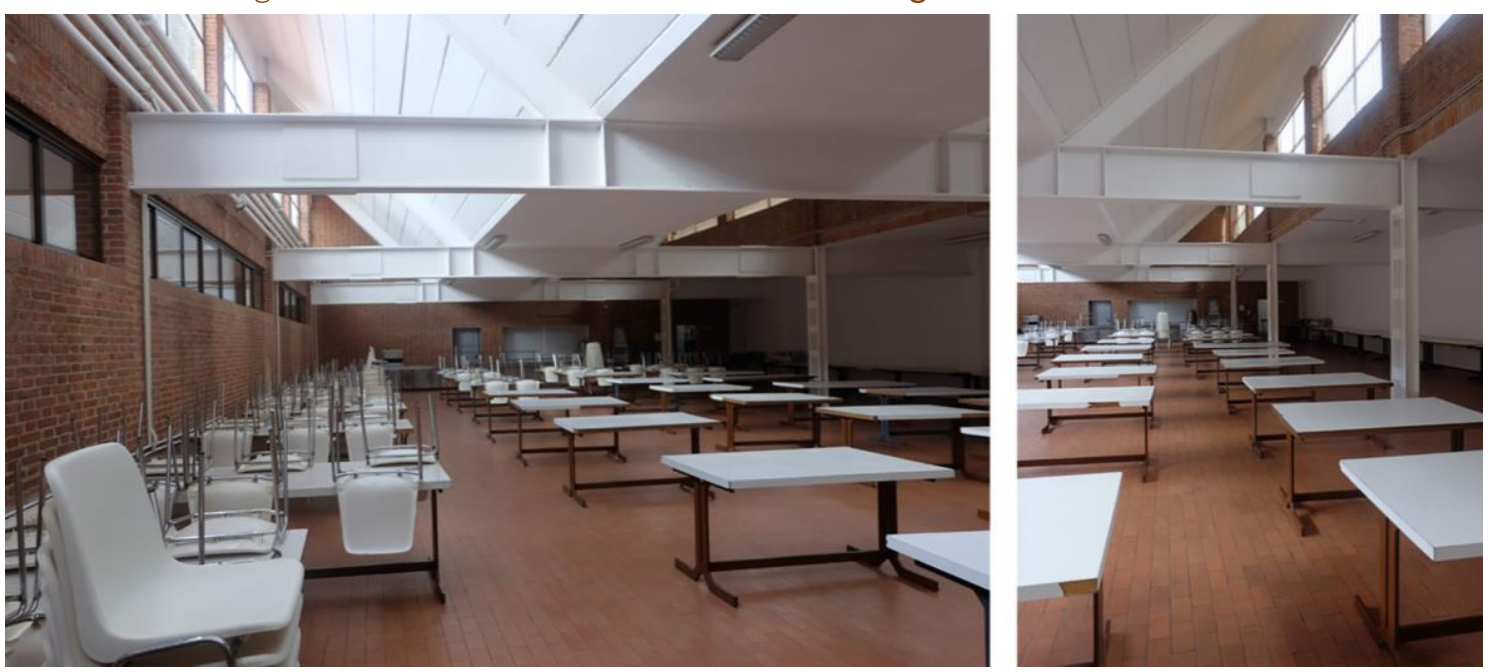

Fuente: Archivo fotográfico de los autores. Fecha fotografías: marzo de 2017.

ACE, 15 (43) CC BY-ND 3.0 ES | UPC Barcelona, España | La Universidad Laboral de Albacete (1974-75), un episodio olvidado en el legado arquitectónico de Julio Cano Lasso. DOI: http://dx.doi.org/10.5821/ace.15.43.7316 


\section{Los subtextos: genealogías, articulación, espacio-luz, materia, cultura}

\subsection{Genealogías modernas}

La Universidad Laboral de Albacete es la última pieza de dos series: la del Ministerio de Trabajo y la del propio arquitecto. La terna de proyectos para Almería, Lardero y Albacete se elabora y se contrata cronológicamente en ese orden, construyéndose en muy poco tiempo. Los programas estaban detallados y los equipamientos urgían por la aplicación de la nueva Ley General de Educación. El proyecto de Albacete está en relación de dependencia con el de Lardero y con el de Almería, al principio de esta serie, en el cual figura también Alberto Campo Baeza quien, como recién titulado, había entrado a trabajar en el estudio de su antiguo profesor.

Por su parte, siendo estudiante, Cano Lasso había colaborado con Fernando Moreno Barberá quien, más tarde, proyectaría cuatro universidades laborales (Blat, 2006). Este maestro desarrolló sus cuatro centros de acuerdo con los principios del Movimiento Moderno, definiendo tramas urbanas abiertas, como la de Cheste (1965-70), en línea con los grandes campus universitarios latinoamericanos de los años 50 (Hitchcock, 1955). Sin embargo, en la universidad de Málaga (1972-82), la última de cuantas realizó, Moreno Barberá ensayaría una propuesta de agrupación de pabellones monofuncionales conectados por un porche a modo de malla reticular, sin jerarquías axiales, dando lugar a un organismo aparentemente unitario frente a la dispersión de los bloques, solución que recuerda algunos de los colegios realizados hacia esos años por Rafael de La Hoz para las Teresianas.

En efecto, entre finales de los 60 y principios de la década siguiente, los complejos docentes (universidades, institutos y colegios) no se conciben tanto como conjuntos de volúmenes aislados cuanto organismos arquitectónicos basculando en torno a un espacio central, condición que comparten la mayoría de las soluciones premiadas en los sucesivos concursos que convoca el Ministerio de Educación cada vez que implanta un nuevo plan educativo (Martínez-Medina et al., 2015), y que posee extraordinarios ejemplos en varios colegios privados, tales como las propuestas de arquitectura escolar de MBM (Martínez-Medina et al., 2015; Durá, 2016) o de Fernández Alba (PérezMoreno, 2018), por citar casos de las Escuelas de Arquitectura de Barcelona y Madrid, respectivamente. Estos nuevos centros acusan una atenta revisión del ideal de la arquitectura orgánica defendido por Bruno Zevi que impactaría en el ámbito español de finales de los años 60 a través de la lectura "operativa" llevada a cabo por Juan Daniel Fullaondo y la revista Nueva Forma (1966-1975) (Pérez-Moreno, 2015, pág. 114).

Fullaondo, quien en "Agonía, Utopía, Renacimiento", uno de sus textos más extensos y comprometidos - publicado, significativamente, en mayo de 1968-, hablaba de un "cambio de paisaje" para referirse a la superación del Movimiento Moderno y a la pluralidad de nuevos discursos y tendencias que habían eclosionado, tanto en el panorama internacional como en el contexto ibérico, trataría de ahondar en las raíces culturales de la modernidad española al tiempo que buscaba claves con las que orientarse en los diversos caminos abiertos en su presente. Así, en su intento por recuperar la "Generación del 25" (fundamentalmente vinculada a arquitectos titulados por la Escuela de Madrid -como prolongación del discurso de Carlos Flores en su libro Arquitectura Española Contemporánea, 1961-), la coloca en el arranque de la modernidad en España, a la que denomina "El Racionalismo Español" (Nueva Forma n.o 33, 1968), una modernidad que no debía ser directamente asimilada a vanguardia (Pérez-Moreno, 2015). El elenco de profesionales que desfilan con sus obras y proyectos en las páginas de la revista sitúa esta corriente moderna en la base metodológica y pedagógica de las generaciones que trabajan desde Madrid en los años posteriores a la Guerra Civil. Entre ellos se incluyen, de modo sintético, en un primer eslabón (años 40 y 50), a Aburto, Cabrero y Fisac, y, en un segundo momento (años 60 y 70), a Corrales y Molezún, De la Sota, Fernández Alba, 
Fernández del Amo, Higueras, Sáenz de Oiza (Martínez-Medina y Gutiérrez-Mozo, 2012) y al propio Cano Lasso. Es común a la mayoría de estos arquitectos con despacho en la capital (aunque la revista preste también especial atención a catalanes como MBM), la construcción de una importante obra con fábricas de ladrillo visto donde se evidencia una elocuente fusión y continuidad de racionalismo y expresionismo organicista como rasgo que, de Fullaondo a Capitel (1991), diversos críticos han considerado distintivo de la denominada Escuela de Madrid.

En este contexto, no resulta extraña la aparición, a principios de 1972, de un número monográfico dedicado a la figura de Cano Lasso, cuyas arquitecturas de esa época, concebidas como organismos articulados y dotados de una materialidad y masividad propias del ladrillo, resultaban afines a los intereses de Fullaondo, a quien el arquitecto, unos meses antes, había reconocido públicamente su admiración por la labor de crítica llevada a cabo desde las páginas de Nueva Forma (Martínez-Medina y Gutiérrez-Mozo, 2012). Cano Lasso entraría, pues, en esta línea que aúna racionalismo español y los intereses plásticos de la Escuela de Madrid. Si bien sus encargos de universidades laborales plantean programas y problemas mucho más complejos que los colegios y centros educativos mencionados anteriormente, por lo que el arquitecto los aborda, fundamentalmente, desde la atención a exigencias funcionales, de escala y de implantación propias, no obsta para que se plantee fructíferas revisiones de algunos principios modernos y tampoco renuncie a incorporar hallazgos compositivos afines a las corrientes organicistas que más atraían la atención de los medios aquellos años.

\subsection{La articulación: forma abierta, volumen cerrado}

Podría pensarse que los proyectos para las universidades laborales de Albacete, Lardero y Almería, considerando especialmente sus plantas salpicadas de patios, hallan una referencia directa en las propuestas de mat-buildings realizadas por Van Eyck (Orfanato Municipal de Ámsterdam, 1955-60) o por el equipo de Candilis, Josic y Woods (Universidad Libre de Berlín, 1963) (Robles II, 2014). Sin embargo, la distribución de las diferentes piezas, agrupadas por funciones, y su sometimiento a un orden riguroso de posición y jerarquía sobre una retícula, vinculan los planteamientos de proyecto a la larga tradición del urbanismo racionalista. De hecho, en estos tres complejos de Cano Lasso, el sistema compositivo es el de un organismo fuertemente articulado cuyos diferentes elementos se relacionan a través de los corredores y espacios de circulación que parten de una gran plaza central alrededor de la cual gravitan los principales volúmenes del conjunto.

Como en su admirado Coderch, los sistemas de crecimiento ocurren de manera similar a la de ciertas obras del maestro catalán: Cano Lasso conecta formas y macla piezas que se materializan en el cruce de ejes de recorrido muy claros, cuyo trazado obedece a una ordenación abstracta de base reticular donde el centro se sitúa de manera estratégica. O, dicho en palabras de su hijo Diego: "la conquista del centro de gravedad compositivo y funcional, búsqueda fundamental [en varias casas mediterráneas de Coderch y en la Universidad Laboral de Almería], se consigue de manera muy trabajada y con mucha racionalidad en ambos arquitectos [cuya obra responde a una misma dualidad] que es esencia de la arquitectura mediterránea en la que el vacío, el patio y la plaza son atrapados dentro de la masa de edificación” (Cano Pintos, 2014, pág. 180). (Figura 10)

En Albacete, el resultado es un edificio aparentemente cerrado, como una pequeña fortaleza, pero pensado para crecer cuando fuese necesario. El programa no se compone desde el todo a las partes, como se venía haciendo en la década de los 60 y de lo cual Moreno Barberá y el tándem Luis Laorga y José López Zanón (Basterra, 2016) dejaron excelentes ejemplos en sus universidades laborales, por ejemplo y respectivamente, de Málaga y Huesca, aunque el propio Laorga, en su Colegio de Nuestra Señora del Recuerdo, en Madrid (1957-58), ya ensaya la fórmula inversa (Durá, Martín y Rangel, 2016). Cano Lasso no clausura el edificio, sino que lo desarrolla a partir de una cuadrícula extensible que permite ir abordando y ajustando el programa, pautado al milímetro en base a las instrucciones

ACE, 15 (4.3) CC BY-ND 3.0 ES | UPC Barcelona, España | La Universidad Laboral de Albacete (1974-75), un episodio 14 olvidado en el legado arquitectónico de Julio Cano Lasso. DOI: http://dx.doi.org/10.5821/ace.15.43.7316 


\section{ACE Architecture, City and Environment}

ministeriales, al tiempo que dibuja un perímetro exterior que, a pesar de su nítida definición, es compatible con una forma arquitectónica abierta a futuras ampliaciones.

Figura 10. Pasos cubiertos entre las aulas y los bloques de la residencia
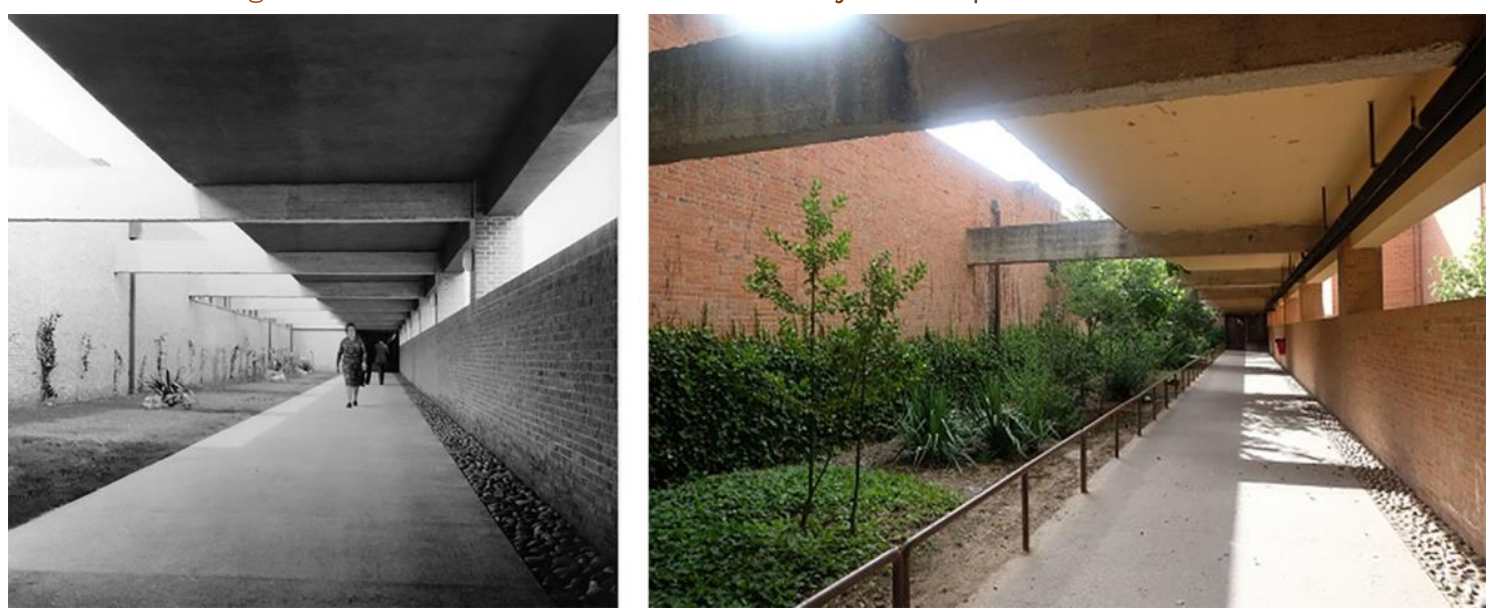

Fuente: Archivo Diego Cano Pintos. Fecha: hacia 1980 (izda.). Archivo de los autores. Fecha: octubre de 2016 (dcha.).

En la Universidad Laboral de Almería, cuyo esquema abstracto de composición, como se ha indicado, se reutiliza para Lardero y Albacete, "cuatro ejes en los que se van insertando los diversos elementos del programa" (Cano, 1993, pág. 33) dan lugar a "una gran plaza porticada" como "lugar de encuentro y relación” (Cano, 1988, pág. 104). En esta plaza que, en Albacete, se transmutará en patio, el orden cartesiano provoca ciertas simetrías a la vez que trata de racionalizar la tradición de la arquitectura vernácula (elemental, prismática y blanca) de esta región de suave orografía y clima desértico, uniendo "lo culto y lo popular en un trasvase recíproco de influencias" (Cano, 1988, pág. 103). Cano Lasso se refería a esta obra como un "proyecto en la tradición de la Arquitectura mediterránea, en cuyas raíces hemos pretendido injertar una arquitectura puramente racionalista, actualizando muchos de los valores de su arquitectura y urbanismo" (Cano, 1995, pág. 216). Por lo tanto, su planta es una trama ordenada a partir de un sistema de ejes ortogonales que organiza las circulaciones (corredores-calles y vestíbulos-plazas) y que deriva de la reinterpretación de los tejidos urbanos y las tradiciones vernáculas de la arquitectura, primero andaluza y, más tarde, en Albacete y Lardero, respectivamente, de La Mancha y La Rioja.

Para articular la Universidad de Almería, el centro de gravedad del conjunto se sitúa en el gran patio de recibimiento a modo de "plaza porticada" (legible tanto como claustro con sus corredores perimetrales abiertos o como plaza mayor con sus pórticos laterales en sombra), alrededor del cual se disponen los demás elementos del programa. Se trata de un espacio urbano sin referentes escalares porque a él solo recaen las embocaduras de los corredores, sin otros huecos ni carpinterías. Esta condición de diseño, que busca crear sombras que mitiguen el calor propio de la zona, se conjuga con una configuración de los volúmenes del conjunto a modo de alcazaba, cuyos lienzos continuos, sin aperturas al exterior, defienden el interior de la luz y el calor implacables de Andalucía.

Esta misma estrategia de concebir una arquitectura introspectiva para hacer frente a las altas temperaturas de Almería se utiliza también en Albacete, aunque con el propósito inverso: proteger del prolongado e intenso frío de La Mancha. Para ello, Cano Lasso convierte de nuevo el gran patio de acceso en el centro de gravedad del conjunto. Si bien, ahora este claustro se cierra, acristalándolo, para que el viento no circule libremente por los corredores, volviéndolos inhóspitos. Bajo este criterio, los cuatro patios de Albacete se cierran sobre sí mismos en aras de un mayor control térmico. Las fachadas de todos estos patios están provistas de carpinterías de última generación e, incluso, la

ACE, 15 (43) CC BY-ND 3.0 ES | UPC Barcelona, España | La Universidad Laboral de Albacete (1974-75), un episodio 15 olvidado en el legado arquitectónico de Julio Cano Lasso. DOI: http://dx.doi.org/10.5821/ace.15.43.7316 
galería superior acristalada - que recuerda otras de Alejandro de la Sota - actúa a modo de invernadero. Si en Almería hay que proteger a los usuarios del exceso de calor y de la luz cegadora de ese rincón del Mediterráneo, invitándoles a apropiarse de un entramado de pequeños oasis, en Albacete se trata de conservar el calor, de distribuirlo al interior y de introducir la luz de invierno, por lo que se recurre a un número mucho más limitado de patios, de mayores dimensiones y acristalados, así como a cubiertas con grandes superficies de vidrio convenientemente orientadas.

De este modo, la reacción frente a lo árido del lugar se concreta en la concepción de un organismo introvertido que resguarde a sus habitantes de las temperaturas extremas de la Meseta. Cano Lasso sigue fielmente su máxima de que la arquitectura no puede ser pensada en abstracto: "lo primero que se debe hacer es situarse en el lugar en que se proyecta y dar respuesta al entorno, bien sea natural o urbano" (Cano, 1995, pág. 17). Por distintas razones climáticas, tanto en Almería como en Albacete, el perímetro exterior se cierra, lo que no obsta para que, en ambos casos, se trate de un sistema arquitectónico con posibilidad de futuro crecimiento basado en la trama que lo sustenta. Como imagen, sendos conjuntos se presentan como una ciudadela fortificada frente a la intemperie del tiempo y del contexto. Ahora bien, si en Almería la opacidad de los volúmenes "encalados, limpios y sencillos", según la memoria del proyecto (Cano, 1976, pág. 80), se aproxima a la "solución de una kashba ordenada por un esquema racional" (Campo, 1997a, pág. 102), en Albacete, como en su complejo de Buitrago del Lozoya, con el que comparte aparejo, los volúmenes de ladrillo tienen algo de "castillo o monasterio, y la intención de extremar la tensión entre una arquitectura intemporal, arraigada en la tierra, con su avanzada función espacial que está en la base del planteamiento del proyecto" (Cano, 1997, pág. 7). (Figura 11)

Figura 11. Central de Comunicaciones por Satélite, Buitrago del Lozoya (1967)

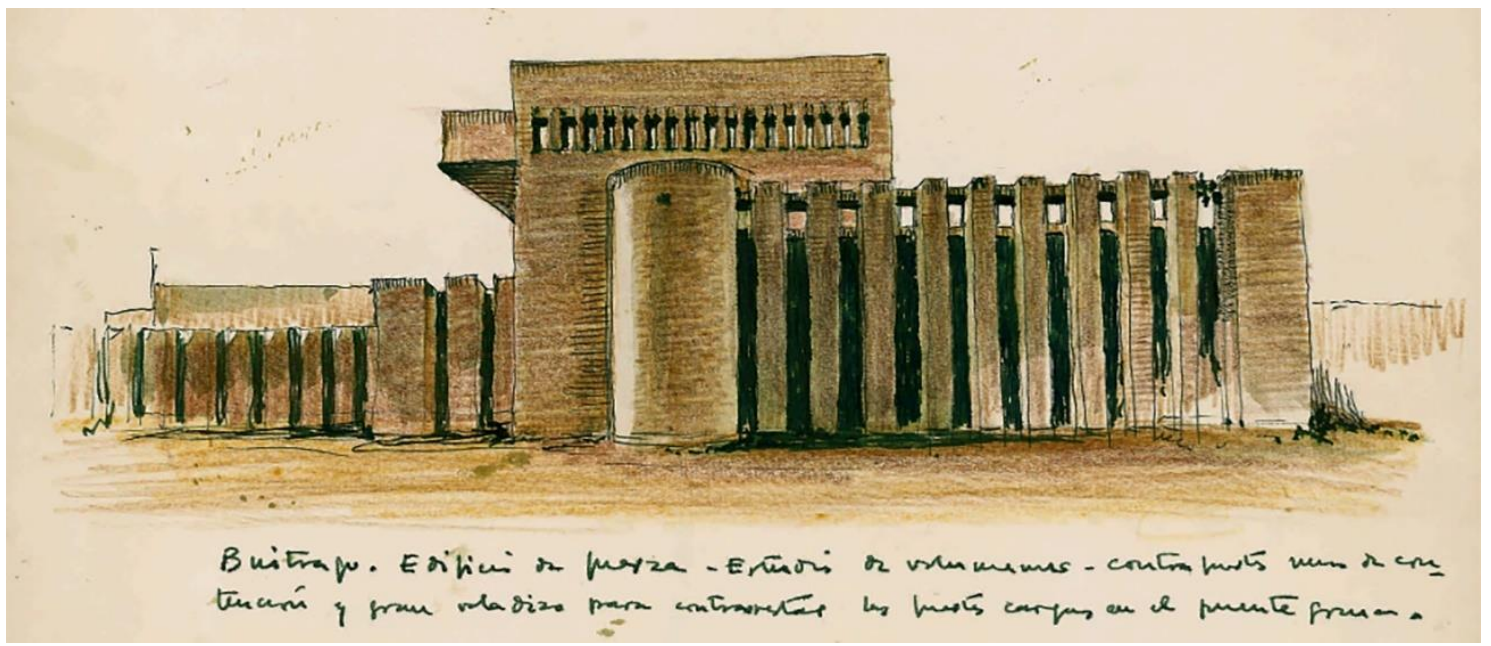

Fuente: Archivo Cano Lasso. Medidas: 28,6×21cm. Descripción: Edificio de fuerza. Estudio de volúmenes. http://lasso.archivosarquitectos.com/es/original/project/13.

\subsection{Espacio e iluminación natural}

Escatimar el espacio cuando este abunda sería un error en el que Cano Lasso está lejos de incurrir. En Albacete hay espacio y luz a raudales. Y, por ello, el autor responde con volúmenes limpios y articulados que configuran esa civitas minima de la que Alberti habla en su De re aedificatoria. Roquette (2010, pág. 469) define las universidades laborales como "ciudades de la arquitectura" y "edificios-ciudad". En Albacete, como la arquitectura no está en situación de asumir la forma de la ciudad en la que se inscribe, crea su propia ciudad. En este caso, se habla de "descampado" a las

ACE, 15 (43) CC BY-ND 3.0 ES | UPC Barcelona, España | La Universidad Laboral de Albacete (1974-75), un episodio 
afueras de la ciudad. A ello alude el autor, con respeto, cuando echa de menos el carácter propio de las ciudades llamadas "históricas" (Cano, 1988, pág. 110). Así, la Universidad Laboral de Albacete recrea en su forma, con una estricta obediencia a las leyes de la razón, un "tipo urbano": el de un poblado en el llano que se abastece a sí mismo, a modo de una moderna aldea manchega que se actualiza con el desarrollo industrial del momento. Pero también, atendiendo a las solicitaciones del programa, de la urbe y del paisaje en el que se asienta, se repliega sobre sí misma, en quietud y en silencio, como lo haría un monasterio en medio del campo con sus claustros y sus corredores, sus salas y sus celdas. Crea así sus propios recintos cerrados de luz y serenidad (Roquette, 2010).

Uno de los elementos más característicos y definitorios de la Universidad Laboral de Albacete es el recurso a una multitud de lucernarios que obedecen a las estrategias del proyecto: exterior cerrado, propio de la arquitectura popular, e interior abierto y luminoso característico de la modernidad. A diferencia de los empleados en Almería, estrechos y profundos para evitar la entrada directa de la luz del sol, aquí se recurre, como ya se ha explicado, a lucernarios superficiales de pequeñas dimensiones en ciertas aulas y a un tipo de lucernario longitudinal de mayores dimensiones, más propio de arquitecturas industriales. Se trata de lucernarios de sección triangular, obtenida al elevar el plano del forjado de cubierta y lograr una superficie de cerramiento vertical completamente acristalada que tendría una temprana referencia en el Assembly Hall de la Escuela de Primaria de Brunswick Park (Londres, 1961), de Stirling y Gowan. Una solución similar configura en la Universidad Laboral de Albacete un paisaje interior donde emergen los IPN blancos de la estructura vista que sostienen los forjados horizontales antes de inclinarse para recibir los amplios planos de vidrio por donde penetra la luz del norte. Este esquema, derivado del orden del esqueleto metálico que recoge de sus maestros Alejandro de la Sota (Gimnasio del Colegio Maravillas, 1962) y, anteriormente, Corrales y Molezún (Instituto de Pisuerga, 1958), es heredero de las soluciones de cerchas dentadas que comienzan a poblar los polígonos de factorías de la década desarrollista. Pero, quizás, la referencia más directa de estos lucernarios que llevan la luz al corazón de la ciudadela universitaria sea la solución de lucernarios lineales, adosados y seriados que emplea Moreno Barberá en los talleres de la Escuela de Ingenieros Agrónomos en Córdoba (1964-70).

\subsection{Materialidad y color}

Parece obvio que un edificio compacto es más barato - aunque no necesariamente económicoque otro disperso. Pero no es menos cierto que la compacidad compromete la función y puede llegar a ser inhabitable. La vida, a solas y en común, es diversidad. Por tanto, Cano Lasso no renuncia a poner cada cosa en su sitio. Sus formas son articuladas y sus espacios complejos. En contrapartida, sus materiales son simples: los justos. Y acreditados: por el uso y por la tradición. "No hay material malo, si se emplea con acierto" (Cano, 1997, pág. 12), afirma. Y el mejor no es el más costoso. Esa austeridad que el arquitecto asume como natural de su oficio, le lleva al encuentro de lo popular, es decir, de la arquitectura anónima, vernácula, "sin pedigri" — diría Rudofsky (1964) —, reparando incluso en la dificultad de encontrar una denominación más apropiada para nombrarla. Aunque, si bien Cano Lasso se declara admirador de lo popular, él es un arquitecto culto y en sus obras, como enuncia en sus escritos, hay una clara voluntad de "arte" (Cano, 1996, pág. 12).

Por una parte, la tradición de estas arquitecturas anónimas se atiene a los recursos que brinda su mismo suelo: arcillas donde hay arcilla, piedra donde hay rocas, madera donde hay bosques, y cañas y barro donde no hay otra cosa. Y por otra, pero por la misma razón, se adhiere al territorio en el que se implanta y del que procede. Cumple así el precepto del primer Wright: identifica el lugar del que materialmente procede. Como algunas aldeas de siempre del Bajo Aragón o de La Rioja, o como algunos poblados de colonización cercanos (Cañada de Agra de Fernández del Amo, Albacete, 1962) (Cordero y Gutiérrez-Mozo, 2020), es tan afín a su tierra, que se suma a ella como un estrato más. Su paisaje no es otro que el paisaje sencillamente artificial (Cano, 1997). En estas arquitecturas, Cano

ACE, 15 (4.3) CC BY-ND 3.0 ES | UPC Barcelona, España | La Universidad Laboral de Albacete (1974-75), un episodio 17 olvidado en el legado arquitectónico de Julio Cano Lasso. DOI: http://dx.doi.org/10.5821/ace.15.43.7316 
Lasso encuentra el perfecto enunciado de sus propios ideales: son clásicas en el sentido de (arque)típicas e intemporales; son verdaderas en la medida en que comparten con la naturaleza materiales, texturas y colores. Entroncan con el lugar, cuyo paisaje modestamente subrayan y, en ocasiones, reinterpretan abstractamente; son auténticas, ya que no tienen doblez y dan testimonio de oficios manuales que, a su vez, acreditan sólidas tradiciones constructivas (Cano, 2001).

Pero, entre ambos polos, el de la tradición, al que la construcción vernácula sirve modestamente, y el de la imaginación que, desde Boullée, la arquitectura culta antepone como la esencia de su práctica, se ofrece la mediación de la razón. Una razón cordial (Cortina, 2007) que no desdeña los fundamentos de la arquitectura popular, que son los del sentido común, y de la cual hay que decir que, si no es racional, en el sentido abstracto que el arquitecto atribuye a la razón, desde luego es razonable. Cano Lasso interpreta la arquitectura popular desde una lógica geométrica y formal, con voluntad de aportar un orden fácilmente comprensible, que entronque con las tradiciones cultas de la arquitectura, sean estas históricas o contemporáneas. Lo que entraña una modestia libre de prejuicios que sabe concertar pasado y futuro en un presente siempre en crisis. Por ello, la prudente selección de materiales que la tradición y el progreso han acumulado, con sus respectivos oficios, tiene que someterse, en su caso, a los imperativos de la forma al servicio de la función, con atención al medio donde se inserta.

Depurándolas con elegancia, Cano Lasso traduce así, o interpreta, con naturalidad —con esa misma "naturalidad, que le hace tantas veces tan cercano a Alvar Aalto" (Campo, 1997b, pág. 44) -, las razones de la tradición popular de la arquitectura desde la razón, geométrica y formal, que subyace en la historia de la arquitectura culta, clásica o moderna. Como defiende su hijo Diego, desde una posición culta y racional, Cano Lasso se interesó por la tradición, tal y como la entendió uno de sus principales referentes intelectuales, Pedro Salinas: "un compendio de saber al que se llega a lo largo de los siglos por medio de la práctica y de un proceso de filtraciones entre la cultura popular y la intelectual", pues tanto para el escritor como para el arquitecto, "nada distingue más el proceso de la tradición que su calidad selectiva y trasvases destilados entre las dos culturas” (Cano Pintos, 2014, pág. 179).

Y, para ello, es decisiva la opción de una paleta muy limitada de tres materiales básicos, la misma a la que recurre tanto en Lardero como en Albacete: el ladrillo cerámico rojo visto, el pavimento marrón de barro cocido y las carpinterías de aluminio anodizado bronce. Significativamente, esta terna se mantiene dentro de una misma gama cromática de tonos cálidos, rojizos, terrosos. (Figura 12)

Figura 12. Universidad Laboral de Albacete. Imagen del patio de acceso
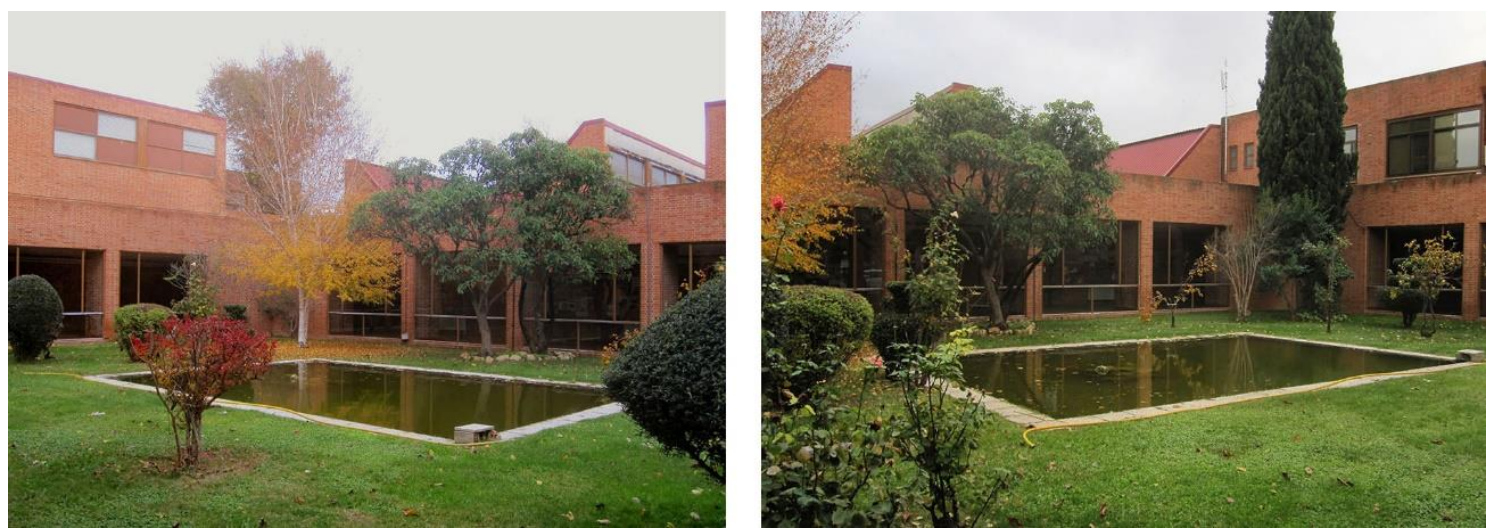

Fuente: Archivo fotográfico de los autores. Fecha: octubre de 2016.

ACE, 15 (43) CC BY-ND 3.0 ES | UPC Barcelona, España | La Universidad Laboral de Albacete (1974-75), un episodio olvidado en el legado arquitectónico de Julio Cano Lasso. DOI: http://dx.doi.org/10.5821/ace.15.43.7316 
El empleo del ladrillo visto, estricto y ejemplar, responde a la voluntad de Cano Lasso de contextualizar la ciudadela universitaria en la propia tierra de La Mancha que muestra el color rojo intenso de su arcilla. Esta, una vez manipulada, se convierte en ladrillos; un material sancionado por la historia, adecuado por la tradición y apropiado para el lugar. Su durabilidad, resistencia, capacidad de adaptación y lento envejecimiento por el uso y el paso del tiempo, lo hacen idóneo tanto para el exterior de los volúmenes como para el sufrido interior de los espacios de esta Universidad Laboral. Además, el aparejo responde en obra a la misma voluntad de orden abstracto de Cano Lasso, de modo que los ladrillos no se tratan como unidades individuales que se resaltan con sus juntas rehundidas, sino que se consideran una entidad por las superficies planas que generan al enrasar sus caras con el mortero y, así, transformarse en paños abstractos que, lejos de parecer ligeros, asientan el complejo en el terreno, dotándolo de un límite contundente y una presencia segura. Pasar de la unidad 'ladrillo' al elemento 'muro' permite al arquitecto manejar el material en planos abstractos, a la vez que hace presente la solidez de la arquitectura y su peso (más evidente por el aparejo a soga y tizón). De este modo, si la ingravidez es propia del Movimiento Moderno, la gravedad es una condición de la arquitectura de todos los tiempos, reuniendo de nuevo tradición y modernidad.

Íntimamente relacionado con el ladrillo que se extiende por todos los cerramientos y particiones y para hacer aún más evidente el protagonismo de la cerámica, el pavimento está resuelto con baldosas de tierra cocida (entonces conocidas comercialmente como 'clínker'), con diferentes texturas (aptas para interior o exterior), en color barro de la misma gama del ladrillo. También se opta por el formato pequeño por su facilidad para solucionar encuentros mediante su acoplamiento a la modulación del conjunto. Se retoma así un material tradicional que la industria ha incorporado a sus procesos de producción mejorando sus características, ampliando su gama de formatos y acabados: abaratándolo, haciéndolo más accesible y, en definitiva, democratizando su larga tradición de uso popular y culto, local e industrial.

El último material de la terna es la carpintería de aluminio anodizado bronce, igualmente cercana a la gama cromática de colores tierra del edificio, un producto recién salido al mercado en el tránsito a los 70 desde las factorías que se implantaron a partir de 1953 con la apertura del país al exterior y la llegada de patentes industriales - piénsese en la planta de Aluminio Ibérico proyectada por el propio Cano Lasso para Alicante (Martínez-Medina et al., 2012) -. El recurso a esta nueva perfilería, mucho más ligera y menos alterable por los agentes atmosféricos, permitía más durabilidad a las superficies acristaladas, menos coste de mantenimiento y mejor rendimiento energético por el sellado de las juntas. La elección de los acabados principales para la Universidad Laboral de Albacete rendía homenaje a la cultura material y constructiva de la Meseta, abrazando, al mismo tiempo, el progreso técnico e industrial de la arquitectura española.

\section{5 ¿Eclecticismo?: Arquitectura moderna y tradición popular}

Inés Martín y Luis Pancorbo han estudiado la atracción de Julio Cano Lasso por las arquitecturas tradicionales, cuyas lecciones se entretejen con la modernidad de su producción. Este interés manifiesto, de acuerdo con ambos investigadores, le habría valido al arquitecto el calificativo de 'ecléctico', ampliamente utilizado por la crítica para referirse a su obra. Si bien "el llamado eclecticismo de Cano es solo la manifestación de tres actitudes en sus proyectos: una cierta disolución del autor dentro de las circunstancias de cada proyecto particular, que conlleva a veces opciones de neutralidad total, de hacer una arquitectura que se integre en un conjunto mayor (el caso de la ciudad histórica), la incorporación de la tradición desde la modernidad (con la necesaria tensión y crítica que supone esta operación) de una forma abierta (apertura de la arquitectura y relación con otras disciplinas) y la utilización de la memoria personal, con toda su impureza, compuesta no solo de lo que pervive y permanece, sino también de lo que ha desaparecido o permanece latente, mediante el método referencial” (Martín y Pancorbo, 2015, pág. 92).

ACE, 15 (4.3) CC BY-ND 3.0 ES | UPC Barcelona, España | La Universidad Laboral de Albacete (1974-75), un episodio olvidado en el legado arquitectónico de Julio Cano Lasso. DOI: http://dx.doi.org/10.5821/ace.15.43.7316 
En efecto, uno de los temas centrales en el pensamiento y en la obra de Julio Cano Lasso es el de la tradición, es decir, la forma en que se transmite y pervive el pasado en el presente, y que, de acuerdo con los citados autores, el arquitecto abordaría a través de dos actitudes divergentes, aunque complementarias. Por un lado, una tradición considerada como flujo continuo desde el pasado, que mantiene características estructurales constantes y que "está sometida a un proceso de selección inmanente a ella que descarta lo superfluo y destila sólo lo valioso y esencial”, revelándose, en el caso de Cano Lasso, en el uso de la tipología como método proyectual. Por otro lado, "matizando y, a veces subvirtiendo la línea de pensamiento fijada en sus propios escritos teóricos, gran parte de la obra del arquitecto habla de otra forma del pasado más compleja y menos estructurada" (Martín y Pancorbo, 2015, pág. 87), de imágenes y referencias que conectan su trabajo con otras obras arquitectónicas o artísticas, presentes o pretéritas. En este segundo caso, se trataría, pues, de una selección subjetiva de referencias a las que el arquitecto recurre como otra "tradición insertada dentro la temporalidad fraccionada de la memoria personal que destruye la historia como continuidad y como inmanencia y se aleja del evolucionismo y las pretensiones teleológicas del anterior supuesto" (Martín y Pancorbo, 2015, pág. 86).

Así, y de acuerdo con la primera acepción, conceptual, que el Diccionario de la Lengua Española da al adjetivo 'ecléctico', Cano Lasso lo sería, literalmente, al adoptar una "postura intermedia entre doctrinas o actitudes diversas”; lo cual dista mucho de la segunda acepción, la que, curiosamente, atribuye específicamente a la arquitectura, definiendo 'eclecticismo' como "combinación de elementos de diversos estilos", propia del revival acrítico y completamente ausente en la obra de Cano Lasso. Él es un arquitecto de su tiempo y, como tal, proyecta desde un método racional que, como se ha dicho, es común a clásicos y modernos (Cano, 2001, pág. 15). Ahora bien, si ecléctico es el "que elige", son su propia cultura, memoria y sensibilidad las que, simultáneamente, discurren a través de ese otro método referencial, operando a través del gusto personal, en el sentido ilustrado del término.

Sin embargo, Cano Lasso es consciente de que los datos de partida del proyecto, a los que él presta la mayor atención y consideración, no los elige el arquitecto, a saber, el lugar y la naturaleza del encargo: él no decide ni "dónde" ni "para qué". Y es a partir de ambas imposiciones como su talento y disposición son puestos a prueba. A partir del sitio, que no ha elegido, y de la función dada, que es inherente al encargo, a él le incumbirá elegir materiales consistentes, económicos, adecuados y duraderos, y formas que satisfagan, no solo el uso y la habitación, sino también el disfrute, con el consiguiente concurso de la sensibilidad, de los espacios al servicio de habitantes, visitantes y transeúntes. Este es el punto crítico, en el cual la economía del buen arquitecto sabe discernir lo que le conviene a la fábrica del edificio, austero cuanto sea necesario, pero sin comprometer su buena conservación y mantenimiento, y lo que reclama la forma para albergar lo mejor posible los modos de vida colectiva antes descritos. En ese discernimiento de lo firme, útil y amable, Cano Lasso no desdeña la lección de la tradición que imparte toda arquitectura popular genuina, que es ecléctica de forma natural: porque da la espalda a las construcciones teóricas, ateniéndose a los materiales disponibles acreditados por el tiempo, a los oficios heredados y transmitidos de generación en generación, sumando saber a saber, y al sentido común que echa mano de todo lo que puede alojar la vida. Podría decirse que Cano Lasso es ecléctico como lo es la arquitectura popular. Pues si algo caracteriza las certezas de esta arquitectura anónima es su arraigo y su adhesión al sitio y su sabio control de las formas en función de su adecuación. Porque esta arquitectura es dignamente 'local', encomiablemente 'funcional' e indiscutiblemente 'universal'.

Pero no es la única tradición a la que apela. También a la del Movimiento Moderno que el arquitecto entiende ya superado como categoría histórica: "El Movimiento Moderno es ya tradición", afirma (Cano, 1995, pág. 17). Y en esta otra tradición, la moderna, la que sostiene su ejercicio más disciplinar, Cano Lasso se posiciona críticamente respecto a la actitud ambivalente del Movimiento Moderno -

ACE, 15 (4.3) CC BY-ND 3.0 ES | UPC Barcelona, España | La Universidad Laboral de Albacete (1974-75), un episodio olvidado en el legado arquitectónico de Julio Cano Lasso. DOI: http://dx.doi.org/10.5821/ace.15.43.7316 
entre la radicalidad de la tabula rasa y su fascinación por ciertas arquitecturas populares, en las que encontró inspiración al tiempo que rechazaba su legado-, con el que se esfuerza en tender puentes: "Así esa contradicción entre la filosofía que inspiraba el Movimiento Moderno y que pretendía prescindir del pasado y de la historia, y esta forma de entender la tradición como principio creador, se resolvió en una Arquitectura que, asumiendo la poética formal del Movimiento Moderno y sus conceptos de funcionalidad y tratando también de incorporar los cambios programáticos y las nuevas tecnologías, no llegó nunca a romper el hilo de comunicación espiritual con el pasado, ni renegó de sus raíces más profundas" (Cano, 1988, pág. 8).

El propio arquitecto reflexiona sobre las ideas, poéticas y referencias de las que se nutren sus proyectos, cuestionándose hasta qué punto esa hibridación entre principios modernos y saberes de la arquitectura popular, enraizada material y espiritualmente en el lugar, y tan diversa como sus diferentes contextos, constituye o no una actitud propia del eclecticismo: "Y entre los parámetros principales que intervienen en cada problema de arquitectura están, además del programa, la influencia del medio, el entorno, las técnicas y materiales disponibles, y las leyes de la economía, entendida en el sentido amplio de las leyes que gobiernan la naturaleza. Y lógicamente la intervención de estos parámetros diversos da lugar a soluciones diversas a partir de los mismos principios. Y esta es la razón del aparente eclecticismo" (Cano, 1995, pág. 22).

Se trata de la postura de un profesional pragmático, sin adhesiones incondicionales a postulados teóricos inquebrantables, realista, pero no por ello cerrada a un caudal de referencias cultas, sino, más bien, todo lo contrario. Fullaondo diría de él que su obra, "más difícil de aprehender interpretativamente de una primera y apresurada observación”, podría quizás examinarse en términos de "naturalidad y realismo" (Fullaondo, 1972, pág. 5), fruto de una paulatina evolución personal. Para el crítico, esta evolución, "desde los acentos más límpidos de la poética neo-racionalista” —que en Cano entiende matizada por otros valores empíricos-, hasta la impactante volumetría de Buitrago, parece reflejar el ascenso de una "soterrada vocación expresionista que, a nivel de objeto, podríamos localizar en multitud de sus episodios" (Fullaondo, 1972, pág. 8), entre los q parece oportuno recordar el énfasis plástico de los estudios en sección de la Universidad Laboral de Albacete. (Figura 13)

Figura 13. Central de Comunicaciones de Buitrago (1967) y Universidad Laboral de Albacete (1975)
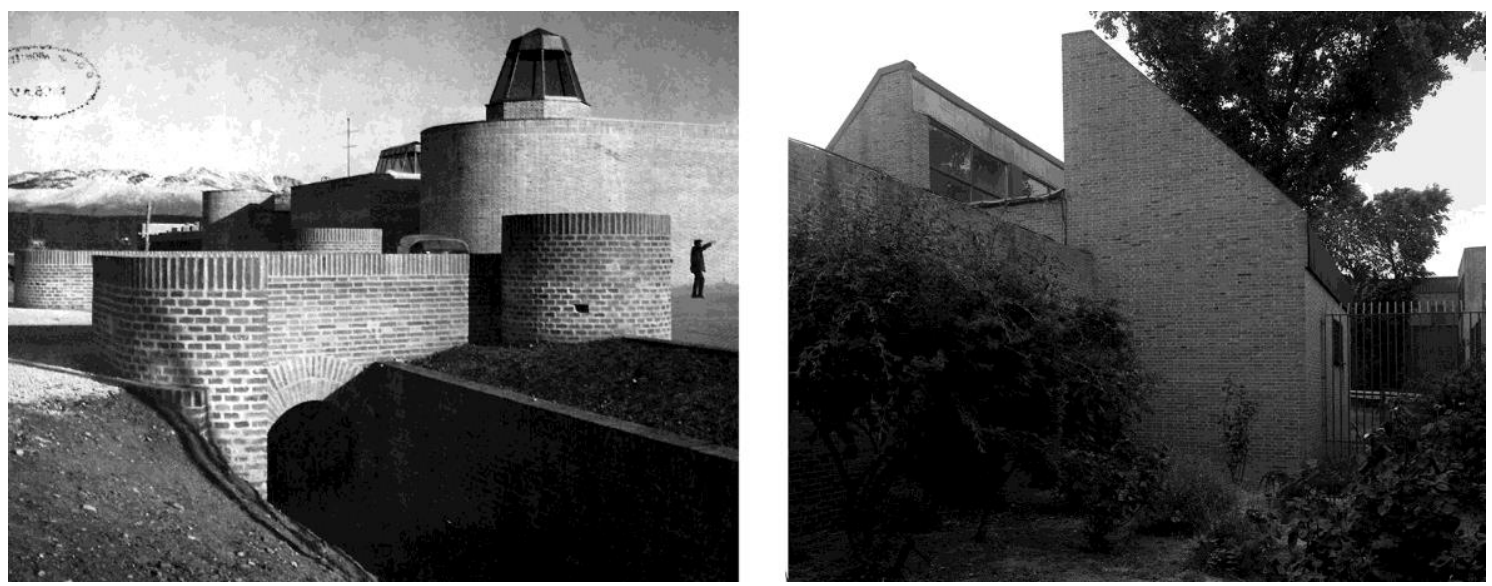

Fuente: Nueva Forma n.o 72-73, pág. 50 (izda.) y archivo de los autores, fotografía de marzo de 2017 (dcha.).

Asumiendo la tesis de Fullaondo, en el mismo número monográfico de Nueva Forma dedicado al arquitecto en 1972, Santiago Amón celebra el eclecticismo y versatilidad de la obra de Cano Lasso como una coherente amalgama de concepciones muy distintas, todas ellas reunidas en "la solución peculiar impresa en la faz de sus edificios: la fidelidad palmaria entre el principio de su formación

ACE, 15 (43) CC BY-ND 3.0 ES | UPC Barcelona, España | La Universidad Laboral de Albacete (1974-75), un episodio 21 olvidado en el legado arquitectónico de Julio Cano Lasso. DOI: $\underline{\text { http://dx.doi.org/10.5821/ace.15.43.7316 }}$ 
teórica y el plano obligado de su acción empírica, la honestidad, a veces impregnada de condescendencia con que la forma, el esqueleto racionalista de lo edificado, asciende al impulso de un sustrato expresionista, y el equilibro, también preciso, refinado, caligráfico, manierista, entre el fundamento de su concepción originaria y el pulso de su propio estilo" (Amón, 1972, pág. 49). Una obra diversa, pues, que puede interpretarse, al mismo tiempo, como racionalista y organicista, en el sentido primigenio del término como respuesta a los condicionantes derivados del contexto físico y cultural. En esta línea de pensamiento, Antón Capitel (1991, pág. 15), escribió elogiosamente: "Cano, un ecléctico verdadero al parecer, mezclaba casi desde un principio la actitud racionalista y la orgánica, fuera porque las utilizase en un mismo tiempo o porque las combinara en una misma obra, acercándose así a casi todos sus compañeros [...] sin parecerse a ninguno. Sin la iluminada actitud metafísica de Sota o Cabrero, sin la obsesiva condición analítica o el talante tardo-juvenil de Oiza, o sin el pasional plasticismo de un Fernández Alba, o un Higueras, Cano pertenece a una actitud de carácter mucho más moderado, moderación armada con una poderosa sensibilidad plástica, además de con la fuerza de una pericia y una sensatez profesional capaz de sopesar y medir la adecuación al tema y al lugar, y elegir, o mezclar, en consecuencia, sus recursos".

Volviendo al modo en que tradiciones modernas (la racionalista, la funcionalista, la orgánica) se entreveran con las populares, el propio arquitecto expresa elocuentemente: "Aunque educado en la Escuela de Arquitectura según una formación académica, pronto me incorporé, como la mayor parte de mi generación, a la poética y principios del Movimiento Moderno, por los cuales me he guiado, aunque sin olvidar mis raíces y mi historia, y he tratado de resolver esa aparente contradicción, en principio, con la idea de que más allá de la tecnología y de las formas está el espíritu, y que por debajo de las corrientes superficiales de cada época existe una corriente profunda cuya continuidad no debe interrumpirse en cada uno de nosotros" (Cano, 1988, pp. 7-8).

No debe interrumpirse, aunque se critique y se trate de superar, pues, para Cano Lasso, como para sus referentes intelectuales, Salinas y Ortega, "la única actitud perniciosa, no es la lucha contra la tradición (que invariablemente acaba sumándose a ella), sino su desconocimiento [...] Para Cano la tradición arquitectónica no se debe recibir acrítica y pasivamente, sino noblemente, mediante el esfuerzo de seleccionar primero dentro de ella lo que puede ser válido para nosotros, y luego mediante la voluntad de moldearla para incorporarla a la actualidad, aportando finalmente algo a su caudal que fluye hacia el futuro" (Martín y Pancorbo, 2015, pág. 93). Su eclecticismo no es nostálgico, acrítico, ni pintoresco, sino metodológico y racional, como resultado de un acercamiento consciente a la tradición, entendiendo que sin acumulación no hay cultura. Pero la mera acumulación de conocimiento pretérito no garantiza la continuidad de la creación. Requiere un devenir y una transformación constantes a través de la "polaridad entre la memoria y el olvido" (Martín y Pancorbo, 2018, pág. 89). Si el olvido es necesario para el recuerdo, la memoria explora y metamorfosea el pasado a través de la interpretación personal de sus huellas (presencias y ausencias) incorporándolas a una nueva vida, la de las obras del presente.

En el pensamiento de Cano Lasso, siguiendo con el argumento de Martín y Pancorbo (2018, pág. 92), junto con sistemas racionales, conviven también "elementos "inconscientes" y otros de carácter "vital", según un modelo alineado con la idea de constelación del Atlas Mnemosyne de Warburg y otras consideraciones, coincidentes con Benjamin y Nietzsche, en cuanto a la "memoria como material" de la arquitectura. El propio Cano Lasso escribiría: "la energía e impulso creadores tienen su origen en algo más profundo y vital que, a veces, se manifiesta incluso en forma no racional y acultural, y que no puede ser eliminado sin privar a la creación arquitectónica de uno de sus estímulos y componentes potencialmente más valioso" (Cano, 1995, pág. 26). De esta manera, existiría un doble ritmo que organiza la transmisión de tradición y que resulta evidente en la obra de Cano Lasso: el de la permanencia de elementos estables (o relato histórico, la memoria colectiva de una sociedad) y el de la pervivencia (en la madeja de la memoria personal, anacrónica, inconsciente e impura): "El

ACE, 15 (4.3) CC BY-ND 3.0 ES | UPC Barcelona, España | La Universidad Laboral de Albacete (1974-75), un episodio olvidado en el legado arquitectónico de Julio Cano Lasso. DOI: http://dx.doi.org/10.5821/ace.15.43.7316 
recuerdo, en vez de tomar la forma ordenada y cronológica de una autobiografía se compone de fragmentos dispersos" (Martín y Pancorbo, 2018, pág. 93). Es decir, de una topología donde, frente al archivo de la tradición como sistema que filtra colectivamente, se opera a través de una colección de referencias personales: "Los objetos ya no aparecen ligados por razones lógicas, sino por campos de sentido que, como campos magnéticos, conectan los elementos entre sí y con un referente enigmático" (Martín y Pancorbo, 2018, pág. 93). Como ejemplo del establecimiento de nuevas relaciones entre los materiales de la memoria de Cano Lasso, de postproducción y recomposición de lo fragmentado, estos autores ilustran su artículo con una comparativa de los cuerpos poligonales del Castillo de Coca, en Segovia, con los lucernarios del cercano Centro de Comunicaciones de Buitrago, a cuya solución el arquitecto volverá puntualmente en la Universidad Laboral de Almería y abandonará, de manera definitiva, durante la ejecución de la obra de Albacete.

Con el paso de los años, con la perspectiva de su propia experiencia y la construcción de una mirada crítica hacia la modernidad, rechazando cualquier interés por lo nuevo por el mero hecho de serlo, Cano Lasso sale al encuentro de la tradición, cuya asimilación, reflexiva y sosegada, le hace entender la enorme responsabilidad de ser depositarios de su legado, pues comprende que en ese flujo transformador que procede del pasado reside cualquier forma de progreso. Así, el arquitecto escribe: "Hubo un tiempo, cuando era joven, que me esforzaba en hacer arquitectura moderna; hoy pienso que esta referencia temporal tiene poca importancia. Me interesa más la obra bien hecha y mi idea de la modernidad ha cambiado [...] Me interesan algunas obras de hoy y muchas del pasado, a veces más vivas que creaciones recientes y siento que todo lo vivo, capaz de emocionarnos, es presente [...] Somos hijos de nuestro tiempo y, aún sin proponérnoslo, nuestra obra llevará indefectiblemente su sello, ya que el legado del pasado, para hacerse presente, ha de ser repensado y sentido por nosotros según nuestras propias circunstancias y vivencias [...] Es más, creo que esta disposición abierta hacia otros tiempos y culturas, superadora de estrechas limitaciones, puede ser una de las características más originales del pensamiento moderno" (Cano, 1991b, pp. 30-31). Es decir, la tradición debe ser reinterpretada ("re-pensada") y sentida ("experimentada"), como algo vivo.

Por tanto, si por ecléctico se entiende el que hace uso de estilos codificados, Cano Lasso no lo es en absoluto. Su razón práctica — “el arquitecto de la sobriedad” lo llamó Vicente Verdú (1996, pág. 54)— y su lógica incondicional —Alvaro Siza (1996, pág. 54) se refirió a él como "el arquitecto del rigor" -, le preservan del menor gesto frívolo hacia las formas heredadas. Así, su apropiación, honesta y precisa, de los saberes compartidos de diversas tradiciones (cultas y populares) y, también, su reelaboración, incuestionablemente libre, de una constelación de imágenes y referencias propias, como insiste Fullaondo, responde a las exigencias de un desarrollo "íntimo, silencioso y personal", a una actitud "sosegada", con la que el arquitecto "sin intervenir directamente en toda la agitada controversia de [su tiempo], ha conseguido serenamente transcribir muchas de las coordenadas que han configurado -y de hecho lo siguen haciendo- nuestro panorama" (Fullaondo, 1972, pág. 8).

\section{Conclusiones: complejidad sin contradicciones}

Si, como se ha visto, para Cano Lasso el lugar es su primer dato, el auténtico punto de partida de su trabajo, en las afueras de Albacete el arquitecto echa de menos un carácter al que remitir y al que acogerse, una referencia - un imaginario o asidero psicológico- que le ayude a orientar geográfica y culturalmente el proyecto. De aquí que, asumiendo su relativo desamparo, trate de hacerse fuerte apelando a la razón funcional y a la materia sin tiempo. Fiel a la consigna unamuniana de que creer es crear, Cano Lasso, creyendo en la ciudad ausente, crea un microcosmos con nombre de Universidad Laboral que surge en lo desolado de la Meseta desde su vocación de urbanizar un territorio suburbano y sin cualidades. Así, el complejo docente funda el lugar y lo habita, se ofrece,

ACE, 15 (4.3) CC BY-ND 3.0 ES | UPC Barcelona, España | La Universidad Laboral de Albacete (1974-75), un episodio olvidado en el legado arquitectónico de Julio Cano Lasso. DOI: $\underline{\text { http://dx.doi.org/10.5821/ace.15.43.7316 }}$ 
como el propio Cano Lasso diría de Almería como "un bastidor en el que otros habían de bordar, un panal en espera de la labor de las abejas...” (Cano, 1993, pág. 33).

En este caso, la metamorfosis del páramo manchego sucede sin ruido mediático, una auténtica "ciudad satélite", taciturna y exacta, materialmente sobria y ordenada en sus formas, pero, sobre todo, generosa en sus espacios. Cinco parámetros le guían para anclar el edificio al contexto: el paisaje, la cultura, el clima, la luz y la materia de la periferia llana de Albacete; el esquema de composición racional, la configuración de una ciudadela autosuficiente, los patios interiores cerrados, la captación de la luz natural y la uniformidad material en acabados que proceden de la tierra, todo ello hibridando lo moderno y lo popular, lo selecto y lo humilde, volviéndolo culto.

Afirma Rafael Moneo (1996, pág. 54), en el obituario que dedicó a Julio Cano Lasso, que el arquitecto “amaba la ciudad". Es una pequeña ciudad discreta de formas cabales, de siempre: clásicas, inteligibles, reconocibles. Y para un propósito social pilar de la modernidad: un centro de enseñanza y de capacitación para obreros. Un ámbito de residencia y estudio, de trabajo y descanso: una "utopía" (Cano, 1991b, pp. 29-32), a la vez laica y monástica. Cano Lasso cierra el ciclo que Luis Moya Blanco, su maestro (Roquette, 2010), había inaugurado en Gijón. Un proyecto, el de las universidades laborales, con carácter público, a cuyo destino universitario deben su nombre: un mundo diminuto. Y Cano Lasso no duda en dispersar este pequeño mundo para ponerlo a disposición de los distintos usos, aunque ello conlleve inevitablemente gastos de acondicionamiento que son inherentes a este tipo de fábricas minuciosamente articuladas. Un programa pormenorizado conduce a un diagrama abierto (sobre formas elementales, aparentemente cerradas) en torno a un sistema de ejes, primarios y secundarios, de estancias y de circulaciones.

La función dispersa la forma disponiéndola en orden cartesiano y jerarquizando su posición. La forma, a su vez, reúne la función y la compone. En ese viaje de ida y vuelta, el proyecto halla el equilibrio entre lo que la economía aconseja y el bienestar agradece: ni la forma se somete al ahorro, ni el espacio se escatima. La austeridad que Cano Lasso se impone a sí mismo, en tanto que arquitecto, e impone a su obra, en cuanto utilidad social, no atañe al espacio y a la luz, es decir, a la posibilidad de disfrutar de esos dones de la naturaleza que Le Corbusier denominaba joies essentielles.

Piensa Cano Lasso que el ahorro también incumbe a la elección de los materiales: una disciplina en la cual la arquitectura popular es maestra reconocida. Esa elección atiende al entorno y al ambiente, a la economía desde luego y al carácter: una universidad laboral es un modo de ser. El acierto en la elección del material fundamental, fácilmente disponible y dependiendo de un oficio diestro asegurado, determina la fortuna y la buena conservación del inmueble. Cano Lasso no duda en este caso en apuntar al ladrillo, material único en lo posible, será la seña de su fábrica (Cano, 2001), la cual refuerza con los otros materiales necesarios: a los muros añade los suelos de barro cocido y los acristalamientos sostenidos por bastidores de aluminio anodizado bronce. El ladrillo es un material intemporal que salta de un lugar a otro y de una época a otra, clásico en el más pleno sentido y popular como la propia tierra que se pisa. Es duradero y se adapta a las geometrías más diversas. Y es cálido a la vez que ofrece solidez y seguridad: la gravedad universal por cercanía y contacto. Además, por si fuera poco, se presta a la práctica de un "racionalismo en ladrillo", como él mismo lo llama a propósito de la Universidad Laboral de Albacete (Cano, 1988, pág. 110).

Es "sobrio y resistente", dice también el autor, y combina a la perfección los caracteres propios de una universidad laboral, como son el industrial y el docente. El ladrillo es moderno (Cano y Adell, 1988) y culto, sin dejar de ser popular. Obedece tanto a la razón como al sentimiento. Es útil, duradero y amable. Y se deja aparejar con una libertad que otros materiales no consienten, haciendo de lo pequeño algo grande, de lo individual algo colectivo. Por consiguiente, es funcional a cualquier escala (Cano, 2014). Y todo ello queda a la vista, lo cual hace honor a la economía de recursos y al gusto

ACE, 15 (4.3) CC BY-ND 3.0 ES | UPC Barcelona, España | La Universidad Laboral de Albacete (1974-75), un episodio 
moderno por lo esencial, escueto y sin adiciones innecesarias. Luego, la forma traduce esa sobriedad en elegancia, la economía en sensibilidad y la ausencia de lo superfluo en su propio ornamento. Así pues, podría concluirse que el organismo arquitectónico de Albacete es una obra sencilla (sin pretensiones mediáticas), austera ( $\sin$ abusos materiales) y culta (sin excesos retóricos): "La arquitectura es arte y es servicio" (Cano, 1988, pág. 5), por el buen oficio de su construcción, por sus justas dimensiones, por la sabia composición de sus partes y por el ejercicio poético de sus formas. "Más allá de la tecnología y de las formas está el espíritu" (Cano, 1988, pág. 8). Cano Lasso no se conforma con hacer las cosas bien, en proyecto y en obra, sino que aspira a dotar a su fábrica de esa poesía que solo quienes la viven y habitan a fondo pueden hacer perceptible con su uso y disfrute en común (Oriol, 1996). (Figura 14).

Figura 14. Universidad Laboral de Albacete. Imágenes históricas: patio docente (izda.) y taller (dcha.)
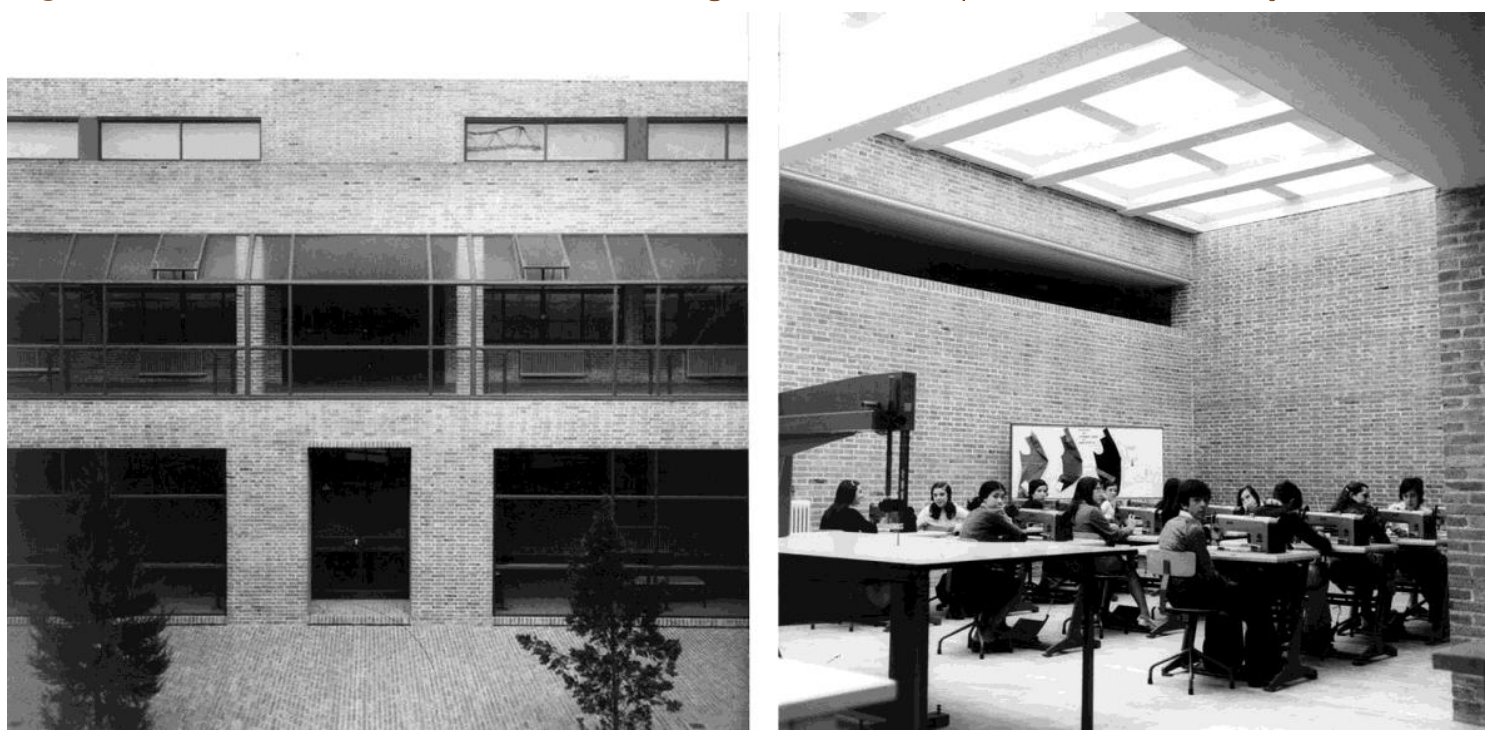

Fuente: Archivo Diego Cano Pintos. Fecha de las fotografías: hacia 1980.

Así pues, el denominado Centro de Universidades Laborales de Albacete, aún hoy emplazado discretamente en la periferia, geográfica y cultural, llana y sin accidentes, de una ciudad sin carácter, puede entenderse como la última pieza del programa formativo de un régimen que se extinguía o como la primera apuesta de un nuevo marco educativo más libre y propicio a una arquitectura más integradora y atenta a sus usuarios. El nombre con el que se denomina, 'centro', y los ciclos formativos a los que atiende desde su origen, eran fruto de la nueva Ley General de Educación de 1970 que consolidaría la enseñanza mixta y sostendría "la aspiración, hoy generalizada, de democratizar la enseñanza” (Ministerio, 1970, 12.525). En esta aspiración, los tres campus laborales analizados, Almería, Lardero y Albacete, comparten hoy el mismo uso como centros de educación secundaria con ramas laborales. En este último caso se trata de una arquitectura que ha sabido aunar tradición e innovación atendiendo a un lugar concreto, aparentemente tan genérico y de tránsito como Albacete, capaz de resistir al tiempo, al alumnado y a las reformas educativas. Asimismo, ha sabido erigirse en modelo para los nuevos centros de enseñanza secundaria fundados en la ciudad a lo largo de las dos décadas siguientes, que han emulado el orden abstracto y la amable materialidad legados por Cano Lasso.

Alejandro de la Sota (2002, pág. 83) afirmó: “la arquitectura, o es popular o intelectual, lo demás es negocio”. La Universidad Laboral de Albacete es, en suma, una obra culta de incuestionable vigencia. Bebe de la tradición e incorpora sus enseñanzas, reuniéndolas con las ideas modernas en un proyecto permeable a las aspiraciones de una sociedad que, tanto entonces como ahora, se hallaba inmersa

ACE, 15 (4.3) CC BY-ND 3.0 ES | UPC Barcelona, España | La Universidad Laboral de Albacete (1974-75), un episodio 25 olvidado en el legado arquitectónico de Julio Cano Lasso. DOI: http://dx.doi.org/10.5821/ace.15.43.7316 
en profundos cambios. Decía André Bretón que "la obra de arte solo tiene valor cuando tiembla de reflejos del futuro" (Benjamin, 1973, pág. 49). Cano Lasso abre en Albacete una puerta al futuro. Por ello, cabría concluir trayendo en favor de esta Universidad Laboral, injustamente olvidada por razón de su ubicación temporal y, sobre todo, geográfica, una reflexión del propio Cano Lasso: "Para que la Arquitectura que hacemos llegue a ser auténtica expresión de nuestra época [...] es preciso que ahonde en la tradición y se incorpore a ella, descienda a la calle y se haga patrimonio de todos, para que, paralelamente a la creación culta de los profesionales, se desarrolle una corriente popular de comprensión primero, de asimilación después y de creación, por último, como ha ocurrido en los momentos de verdadera plenitud" (Cano, 1961, pág. 21).

\section{Agradecimientos}

Deseamos agradecer a Ramón Campomanes su atención para responder a cuantas preguntas sobre el proyecto y su documentación le han sido planteadas con objeto de este artículo. También, y muy especialmente, a Diego Cano Pintos por haber puesto a disposición de esta investigación todo el material gráfico y fotográfico original del proyecto de la Universidad Laboral de Albacete que obra en su poder, así como su aliento y su ánimo para estudiar y difundir la obra de su padre.

\section{Autoría}

Los tres autores han participado plena y cooperativamente en la concepción y el desarrollo de esta investigación. Además, también han elaborado conjuntamente la bibliografía e identificado los parámetros para el análisis. María-Elia Gutiérrez-Mozo ha puesto mayor énfasis en el marco conceptual, el diseño de la metodología de estudio y la producción de la documentación gráfica. José Parra-Martínez en el significado y alcance de lo clásico, lo moderno y lo popular en la obra de Julio Cano Lasso y en la revisión del manuscrito final. Y Andrés Martínez-Medina en toda la serie de referencias (propias del autor, nacionales e internacionales de otros autores) que gravitan sobre la Universidad Laboral de Albacete.

Conflicto de intereses: Los autores declaran que no hay conflicto de intereses.

\section{Bibliografía}

(12 de octubre, 1975). Fernando Suárez inaugura la Universidad Laboral de Albacete. ABC, 10.

Amón, S. (1972). La arquitectura de Julio Cano Lasso: realismo, expresionismo, manierismo. Nueva Forma, (72-73, monográfico Julio Cano Lasso), 48-52.

Arnau Amo, J. (Ed.). (2010). 70 años de arquitectura en Albacete: 1936-2006. Toledo, España: Colegio Oficial de Arquitectos de Castilla La Mancha.

Basterra Ederra, P. (2012). Las inexistentes universidades laborales y su difusión en las revistas de arquitectura españolas, 1952-1976. En B. Colomina; J. J. Lahuerta; J. M. Otxotorena y J. M. Pozo (Eds.), Las revistas de arquitectura (1900-1975): crónicas, manifiestos, propaganda (pp. 373-380). Pamplona, España: T6 Ediciones y Escuela de Arquitectura de la Universidad de Navarra.

Basterra Ederra, P. (2016). Las universidades laborales de Luis Laorga y José López Zanón: estudios sobre el módulo. Ra. Revista de Arquitectura, (18), 89-96. DOI: https://dx.doi.org/10.15581/014.18.89-96

ACE, 15 (4.3) CC BY-ND 3.0 ES | UPC Barcelona, España | La Universidad Laboral de Albacete (1974-75), un episodio

olvidado en el legado arquitectónico de Julio Cano Lasso. DOI: $\underline{\text { http://dx.doi.org/10.5821/ace.15.43.7316 }}$ 
Benjamin, W. (1973). Discursos Interrumpidos I. Madrid, España: Taurus.

Blat Pizarro, J. (2006). Fernando Moreno Barberá. Modernidad y Arquitectura. Barcelona, España: Fundación Caja de Arquitectos.

Campo Baeza, A. (1997a). Campo Baeza. Madrid, España: Munilla-Lería.

Campo Baeza, A. (1997b). La belleza sosegada. Sobre la casa de Julio Cano Lasso. Madrid. 1955. Arquitectura, (309), 42-44.

Cano Lasso, J. (1976). Concurso Nacional de Arquitectura 1975. Arquitectura, (198), 79-82.

Cano Lasso, J. (1980). Julio Cano Lasso, arquitecto. Madrid, España: Xarait.

Cano Lasso, J. (1985). La ciudad y su paisaje. Madrid, España: Cano Lasso, Julio.

Cano Lasso, J. (1988). Cano Lasso: arquitecto. Madrid, España: Fundación Antonio Camuñas.

Cano Lasso, J. (1991a). El ladrillo, material intemporal. Arquitectos (CSCAE), (123, especial Julio Cano Lasso 1 (1920-1975), Medalla de Oro de la Arquitectura), 42.

Cano Lasso, J. (1991b). El regreso al Paraíso: Utopía. Arquitectos (CSCAE), (123, especial Julio Cano Lasso 1 (1920-1975), Medalla de Oro de la Arquitectura), 29-32.

Cano Lasso, J. (1993). Universidad Laboral de Almería. Periferia (12), 33.

Cano Lasso, J. (1995). Cano Lasso. 1949-1995. Madrid, España: Ministerio de Obras Públicas, Transportes y Medio Ambiente.

Cano Lasso, J. (1996). Conversaciones con un arquitecto del pasado: diálogo de la técnica y el espíritu. Madrid, España: Fundación Esteyco.

Cano Lasso, J. (1997). Mi visión de la arquitectura. Pamplona, España: T6 Ediciones.

Cano Lasso, J. (2001) (1a ed. 1995). Estudio Cano Lasso. Madrid, España: Munilla-Lería.

Cano Lasso, J. (2003). Universidad Laboral de Orense. Pamplona, España: T6 Ediciones.

Cano Lasso, J. et al. (1961). Panorama de la Arquitectura en 1960. Arquitectura, (30), 2-26.

Cano Lasso, J. y Adell, J. M. (1988). El ladrillo, material moderno. Madrid, España: Hispalyt.

Cano Lasso, J.; Pisapia, P. y Venezia, F. (1996). Estudio Cano Lasso. Milano, Italia: Electa.

Cano Pintos, D. (2014). Tradición y modernidad en la obra de Cano Lasso. Vigencia de su pensamiento. En T. Couceiro (Coord.), I Congreso Pioneros de la Arquitectura Moderna Española: Vigencia de su pensamiento y obra (actas digitales) (pp. 373-380). Madrid, España: Fundación Alejandro de la Sota. Recuperado de https://dialnet.unirioja.es/servlet/articulo?codigo=5599651

Capitel, A. (1991). Notas sobre la figura de Julio Cano Lasso en la arquitectura española. Arquitectos (CSCAE), (123, especial Julio Cano Lasso 1 (1920-1975), Medalla de Oro de la Arquitectura), 14-21.

ACE, 15 (4.3) CC BY-ND 3.0 ES | UPC Barcelona, España | La Universidad Laboral de Albacete (1974-75), un episodio 27 olvidado en el legado arquitectónico de Julio Cano Lasso. DOI: http://dx.doi.org/10.5821/ace.15.43.7316 
Centellas, M. (1993). Universidad Laboral de Almería. Periferia (12), 17.

Cordero, Á. y Gutiérrez-Mozo, M.E. (2020). Cañada de Agra, composing with topography and landscape. VLC arquitectura. Research Journal, (7.1.), 123-143. DOI: https://dx.doi.org/10.4995/vlc.2020.10991

Cortina Orts, A. (2007). Ética de la razón cordial: educar en la ciudadanía para el siglo XXI. Oviedo, España: Noble.

CSCAE (Ed.) (1992). Julio Cano Lasso: Medalla de Oro de la Arquitectura 1991. Madrid, España: Consejo Superior de los Colegios de Arquitectos de España.

Chueca Goitia, F. (1977). La destrucción del legado urbanístico español. Madrid, España: Espasa-Calpe, Colección Boreal.

De la Joya, R. y Barbero, M. (1959). Viviendas en Albacete. Arquitectura, (2), 21-22.

De la Sota, A. (2002). Escritos, conversaciones, conferencias. Barcelona, España: Gustavo Gili.

Durá Gúrpide, I. (2016). La arquitectura escolar de Martorell, Bohigas y Mackay. El modelo concentrado como oportunidad educativa. Ra. Revista de Arquitectura, 18, 71-80. DOI: https://dx.doi.org/10.15581/014.18.71-80

Durá, I; Martín, C. y Rangel, B. (2016). El Colegio Nuestra Señora del Recuerdo de Luis Laorga, Madrid, 1957-1958. ACE: Architecture, City and Environment, (11.31), 71-92. DOI: https://dx.doi.org/10.5821/ace.11.31.3975

Flores, C. (1961). Arquitectura Española Contemporánea. Madrid, España: Aguilar.

Fullaondo, J. D. (1968). Agonía, Utopía, Renacimiento. Nueva Forma, (28), 1-150.

Fullaondo, J. D. (1972). En torno a Julio Cano Lasso. Nueva Forma, (72-73, monográfico Julio Cano Lasso), 2, 5 y 8.

García-Pozuelo Asins, D. y Hernández Vitoria, E. (1980). Arquitectura de Logroño. Logroño, España: Colegio Oficial de Arquitectos de Aragón y La Rioja.

Gutiérrez-Mozo, M. E. (2004). Paseos de Arquitectura por la Ciudad de Albacete. De la llustración a la Modernidad. Albacete, España: La Siesta del Lobo.

Gutiérrez-Mozo, M. E. y Arnau Amo, J. (2019). In defence of the sketch: City and Landscape in the Architecture of Julio Cano Lasso. Disegnarecon, (22), 8.1-8.20. Recuperado de http://disegnarecon.univaq.it/ojs/index.php/disegnarecon/article/view/515

Hitchcock, H. R. (1955). Latin American Architecture since 1945. New York, United States: The Museum of Modern Art.

Ley 14/1970, de 4 de agosto, General de Educación y Financiamiento de la Reforma Educativa. Boletín Oficial del Estado, núm. 187, de 6 de agosto de 1970, pp. 12525-12546. Recuperado de https://www.boe.es/boe/dias/1970/08/06/pdfs/A12525-12546.pdf 
Martín Robles, I. y Pancorbo Crespo, L. (2015). La tradición en el pensamiento arquitectónico de Julio Cano Lasso. La tradición como sistema. ZARCH, (4), 86-97. Recuperado de https://zarch.unizar.es/index.php/es/numeros/numeros-publicados/numero-4

Martín Robles, I. y Pancorbo Crespo, L. (2018). La tradición en Julio Cano Lasso. La tradición como supervivencia. Rita, (10), 88-98.

Martínez-Medina, A. y Gutiérrez-Mozo, M. E. (2012). "Nuevas Forma, Nueva Forma: Revistas de Arquitectura”. En B. Colomina; J. J. Lahuerta; J. M. Otxotorena y J. M. Pozo (Eds.), Las revistas de arquitectura (1900-1975): crónicas, manifiestos, propaganda (pp. 687-694). Pamplona, España: T6 Ediciones y Escuela de Arquitectura de la Universidad de Navarra.

Martínez-Medina, A.; Oliva Meyer, J. y Oliver Ramírez, J. L. (2012). "La factoría del Aluminio Ibérico: maquinaria de la metrópoli". En Landrove, S. (Ed.), La fábrica paradigma de la modernidad. A fábrica, paradigma da modernidad (pp. 103-108). Barcelona, España: Fundación DOCOMOMO Ibérico.

Martínez-Medina, A.; Oliva Meyer, J. y Oliver Ramírez, J. L. (2015). "Sincronías entre ciclos educativos, métodos pedagógicos y arquitecturas escolares". En: AA.VV. La Arquitectura del Movimiento Moderno y la Educación (pp. 43-50). Madrid-Málaga, España: M. de Educación Cultura y Deporte, Junta de Andalucía y Fundación DOCOMOMO Ibérico.

Moneo, R. (10 de diciembre, 1996). Acicate para nuestro trabajo cotidiano como arquitectos. $A B C, 54$.

Oriol, M. de. (10 de diciembre, 1996). Una obra cargada de amor. ABC, 54.

Pérez-Moreno, L. C. (2015) Fullaondo y la revista Nueva Forma. Aportaciones para la construcción de una cultura arquitectónica en España (1966-1975). Alzuza (Navarra), España: Museo Jorge Oteiza.

Pérez-Moreno, L. C. (2018). Vestigios de Alvar Aalto en la opera prima de Antonio Fernández Alba (1959-62). VLC arquitectura, 5(1), 63-94. DOI: https://dx.doi.org/10.4995/vlc.2018.7720

Pié, R. y Rubiralta, M. (2019). Introducción a la sección especial. El alojamiento universitario en España. ACE: Architecture, City and Environment, (14)40, 193-202. DOI: https://dx.doi.org/10.5821/ace.14.40.6766

Río Vázquez, A. S. (2011). Las Universidades Laborales Gallegas. A Coruña, España: Colegio Oficial de Arquitectos de Galicia.

Robles Cardona, M. Á. (2014). La arquitectura de las Universidades Laborales españolas (1946-1978) (tesis doctoral inédita). Barcelona, España: Universidad Politécnica de Cataluña. Recuperado de http://upcommons.upc.edu/handle/2117/95461

Roquette Rodríguez-Villamil, J. L. (2010) La arquitectura de Julio Cano Lasso (tesis doctoral inédita). Pamplona, España: Escuela Técnica Superior de Arquitectura de la Universidad de Navarra.

Rudofsky, B. (1964). Architecture Without Architects. An Introduction to Non-Pedigreed Architecture. New York, United States: The Museum of Modern Art.

Siza, A. (10 de diciembre, 1996). El arquitecto del rigor. ABC, 54.

Stirling, J. (1964). Facultad de Historia de la Universidad de Cambridge (Reino Unido). Arquitectura, (67), 25-26.

ACE, 15 (4.3) CC BY-ND 3.0 ES | UPC Barcelona, España | La Universidad Laboral de Albacete (1974-75), un episodio

olvidado en el legado arquitectónico de Julio Cano Lasso. DOI: $\underline{\text { http://dx.doi.org/10.5821/ace.15.43.7316 }}$ 
Stirling, J. y Gowan, J. (1964). Escuela de Ingeniería. Universidad de Leicester (Reino Unido). Arquitectura, (67), 18-24.

Valero de la Rosa, E. (2015). El Urbanismo en Albacete en la Baja Edad Media. Albacete, España: Instituto de Estudios Albacetenses "Don Juan Manuel".

Valero Ramos, E. (2008). Universidad Laboral de Almería: 1971-1974: Julio Cano Lasso, Alberto Campo Baeza, Miguel Martín Escanciano, Antonio Más Guindal. Almería, España: Colegio de Arquitectos de Almería.

Verdú, V. (10 de diciembre, 1996). Muere Cano Lasso, el arquitecto de la sobriedad. El País. Recuperado de http://elpais.com/diario/1996/12/10/cultura/850172401 850215.html

Vreeze, N. de y Ouwehand, A. (2007). La Escuela de Ámsterdam, la belleza como ideario social. ACE: Architecture, City and Environment, 2(4), 487-496. DOI: https://dx.doi.org/10.5821/ace.v2i4.2386

Zafrilla Tobarra, R. (1998). Universidades laborales, un proyecto educativo falangista para el mundo obrero (1955-1978): aproximación histórica. Cuenca, España: Universidad de Castilla La Mancha. 